\title{
Antlion Optimizer For Effective Integration Of Distributed Generation In Radial Electrical Distribution Networks
}

\author{
A. A. Tawfiq ${ }^{1}$ \\ Electrical Power and Machines Department \\ Faculty of Engineering, Zagazig University \\ Sharkia, Egypt \\ aimantowfic@yahoo.com \\ M. A. El-Hameed ${ }^{2}$ \\ Electrical Power and Machines Department \\ Faculty of Engineering, Zagazig University \\ Sharkia, Egypt \\ m_a_elhameed@yahoo.com
}

\begin{abstract}
The vast growing technologies in the field of renewable energy sources changed the configuration of modern distribution systems to include distributed generation powered by renewable sources. There are different types of distributed generation sources available for integration; all of them are sources of active power, while some types have a little contribution in reactive power production, others are either sources or sinks of reactive power. These varieties of distributed generation sources result in different impact on distribution systems performance regarding losses, voltage profile, voltage stability, and operating cost. The aim of this paper is to optimize the performance of radial distribution systems integrated with different types of distributed generation using antlion optimizer considering the daily load profile. Objectives considered are minimizing losses and enhancing voltage stability indices. Moreover, running cost with different types of distributed generation is evaluated. The proposed method is tested on IEEE 33, 69 and 118 bus systems, comparisons among the effects of different distributed generation types on radial distribution systems performance are in place. Comparing results obtained by the proposed method with those published in literature proved the powerfulness of the proposed method to determine competitive solutions with respect to other modern metaheuristic optimization methods.
\end{abstract}

Index Terms - antlion optimizer, distributed generation, radial distribution systems, reactive power capability.

\section{INTRODUCTION}

Radial distribution systems (RDS) performance optimization using distributed generation (DG) is an area of research for the last few decades. Developments in renewable sources technologies and metaheuristic optimization tools

\author{
A. A. El- Gawad ${ }^{3}$ \\ Electrical Power and Machines Department \\ Faculty of Engineering, Zagazig University \\ Sharkia, Egypt
}

attract researchers to dig more for better enhancement in RDS operation. There are different types of DG sources available for integration with RDS, these source have different contribution in reactive power injection. For example, photovoltaic based type is considered as a source of active power only and may be equipped with shunt capacitor to develop reactive power as well, wind driven asynchronous generators are sinks of reactive power as they withdraw the magnetizing current from the network, and wind driven synchronous generators can vary their reactive power according to their field current.

In the past few years, researchers focused on DG allocation in radial distribution systems using metaheuristic methods, some of them modeled the problem as a one objective task, and others considered the multi objective cases. For example, in [1]-[3] back tracking search algorithm is utilized for multi-objective DG optimal allocation for 33 and 94-buses RDNs, and 69 buses. Optimum size and location of DG for 33 and 69-node RDNs is investigated in [4] to improve losses and voltage profile. In [5] the maximum cost saving over the time for optimal DGs connected with 33 and 69-node RDNs is presented. [6]-[7] used Cuckoo search optimization algorithm to improve the system voltage profile and minimizing the losses using multi-objective for 33 and 69node systems. In [8] Pareto Frontier Differential Evolution (PFDE) algorithm is examined to optimize active power loss reduction, voltage profile improvement, and voltage regulation for 33 and 69-node RDNs. Authors in [9] used an exhaustive OPF algorithm to allocate an optimal mix of different DG types with various generation capabilities for 33 and 69-node RDNs. [10]-[12] tested the Particle Swarm Optimization (PSO) to determine the location, type and size of DG for 15node RDNs and 33-buses, while in [13] the PSO is examined to determine the optimal location and sizing of DG for 10 and 
123-node RDNs. Improved Analytical (IA) method to calculate the optimal size of four different DG types and determine the best location for DG for 16, 33, 69, 37 and 118 RDNs is found in [14], [15]. References [16]-[18] used Improved Harmony Search (IHS) Algorithm to minimize total losses for 69-node, 13-buses Chinese city, and 12-node. In [19] Optimal Power Flow (OPF) is utilized to minimize capital operation and maintenance costs for 9-node system. [20] used the Fuzzy adaptation of evolutionary programming to minimize the system loss and DG's capital costs by optimal sitting and sizing of DGs for 34-node RDN. In [21] analytical expression algorithm is applied to install DG in the 33-node system and optimum location is determined.

Ant Lion Optimizer (ALO) is an optimizer algorithm proposed by Seyedali Mirjalili in 2015. The ALO algorithm simulates the mechanism of ant lions in hunting the prey. This algorithm has been applied successfully in some engineering problems as in [22]-[24].

In this work, DGs are classified as:

PV generating unit, this type of DG produce only real power (P), called type-1 DG.

Wind turbines driven synchronous generators that have converters, this type of DG produce both real and reactive power $(\mathrm{P}+\mathrm{jQ})$, called type-2 DG.

Wind turbines which induction generators at fixed speed, this type of DG produce real power and consumes reactive power (P-jQ), called type-3 DG. The reactive power for this type is obtained by Eq. (1) [25]-[26].

$$
\mathrm{Q}_{\mathrm{DG}}=-\left(0.05+0.04 \mathrm{P}_{\mathrm{DG}}^{2}\right)
$$

Where $\mathrm{P}_{\mathrm{DG}}$ and $\mathrm{Q}_{\mathrm{DG}}$; are the $\mathrm{DG}$ active and reactive power (in Mw and Mvar).

The varieties in DG sources regarding reactive power capability and their running costs is the motivation of this paper to optimize the performance of RDS using these types of DG and to compare between their effects on RDS performance with variable load profile. The 33-node, 69-node and 118-node RDNs are selected to elucidate the features of the Back/Forward Sweep [27] and ALO algorithm [28], and examine their performances. The proposed methods are coded using MATLAB statements release MATHWORKS_R2011A [29]. Numerical simulations are executed on a Lenovo laptop with processor intel $\AA^{\circledR}$ core $^{\mathrm{TM}} \mathrm{i} 3-4030 \mathrm{u}$ CPU@ $1.90 \mathrm{GHz}$. With installed memory (RAM) 4.00GB.

\section{PROBLEM DESCRIPTION}

Fig 1 shows a two-bus subsystem as a part of RDS. Active and reactive power losses in line i-j are given by Eqs. (2), (3).

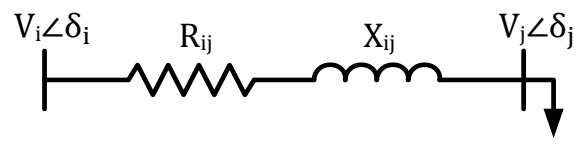

Figure 1. Two-bus subsystem as a part of RDNs

$$
\begin{gathered}
P_{i j \text { loss }}=\left|I_{i j}\right|^{2} R_{i j}=\frac{P_{\text {effj }}^{2}+Q_{e f f j}^{2}}{\left|V_{j}\right|^{2}} \times R_{i j} \\
Q_{i j \text { loss }}=\left|I_{i j}\right|^{2} X_{i j}=\frac{P_{\text {effj }}^{2}+Q_{\text {effj }}^{2}}{\left|V_{j}\right|^{2}} \times X_{i j}
\end{gathered}
$$

Where $\mathrm{P}_{\mathrm{ij}}$ loss and $\mathrm{Q}_{\mathrm{ij} \text { loss }}$; the active and reactive losses in branch $\mathrm{ij}, \mathrm{I}_{\mathrm{ij}}$; current in the branch $\mathrm{ij}, \mathrm{R}_{\mathrm{ij}}$ and $\mathrm{X}_{\mathrm{ij}}$; resistance and inductive reactance of branch $\mathrm{ij}$.

The total voltage deviation (TVD) is used to indicate the improvement in the bus voltage profile and calculated by using Eq. (4).

$\operatorname{TVD}=\sum_{\mathrm{i}=1}^{\mathrm{N}}|| \mathrm{v}_{\text {ref }}|-| \mathrm{v}_{\mathrm{i}}|| \quad \mathrm{i}=1,2, \ldots, \mathrm{N}$

Where $\left|\mathrm{V}_{\text {ref }}\right|$; is the reference voltage magnitude (assumed 1p.u.), N; is the number of network buses, $\mathrm{V}_{\mathrm{i}}$; is the voltage of bus $\mathrm{i}$.

The running cost of DG consists of two main elements operation and maintenance cost. The running cost is calculating by using Eq. (5).

$$
\mathrm{C}_{\mathrm{RunDG}}=\mathrm{DG}_{\text {cost } / \mathrm{kW} . \mathrm{year}} * \mathrm{DG}_{\text {capacity }}
$$

Where $\mathrm{C}_{\mathrm{RunDG}}$; is the running cost of $\mathrm{DG}, \mathrm{DG}_{\text {cost } / \mathrm{kW} \text {.year }}$; is operation and maintenance cost of $\mathrm{DG}$ per $\mathrm{kW}$ per year.

The running cost of PV-DG with ratings from 0.1-1, and 1-10 MW are 19 and $16 \$ / \mathrm{kW}$.year, respectively, and wind turbine-DG with ratings from $0.01-0.1,0.1-1$, and $1-10$ are 35 , 31 and $32.5 \$ / \mathrm{kW}$.year [30]. The net saving in RDS running cost is the difference between saving costs when DG installed and running cost of DG only, as given by Eq. (6).

Net saving cost $\left(\frac{\$}{\text { year }}\right)$
$=$ Saving Cost $(\$ /$ year $)-$ CRunDG (\$/year)

Distribution systems are radial in the nature and has a high $\mathrm{R} / \mathrm{X}$ ratio. Backward/forward sweep algorithm load flow method [27] is used to overcome that problem which may result in divergence of ordinary loaf flow solution methods.

\section{ANTLION OPTIMIZER}

ALO algorithm simulates the mechanism of ant lions in hunting a prey. This simulation start the mechanism by random walks to catch the point randomly, random walks represent as in Eq. (7) 


$$
\begin{aligned}
& X\left(t_{c i}\right) \\
& =\left[\begin{array}{c}
0, \operatorname{Cum}_{\text {Sum }}\left(2 r\left(t_{c i 1}\right)-1\right), \operatorname{Cum}_{\text {Sum }}\left(2 r\left(t_{c i 2}\right)-1\right), \\
\ldots, \operatorname{Cum}_{\text {Sum }}\left(2 r\left(t_{\text {cin }}\right)-1\right)
\end{array}\right]
\end{aligned}
$$

Where Cumsum; calculates the cumulative sum, $\mathrm{n}$; is the maximum number of iteration, $\mathrm{t}_{\mathrm{ci}}$; trying to catch the aim within uniform area distribution from 0 to $1, r\left(t_{c i}\right)$; is a random function given by:

$$
=\left\{\begin{array}{cc}
1 & r\left(t_{\text {ci }}\right) \\
0 & \text { if rand }>0.5
\end{array}\right.
$$

The position of ants is presented with the matrix in Eq. (9).

$$
\mathrm{M}_{\mathrm{Ant}}=\left[\begin{array}{ccc}
\mathrm{A}_{1,1} & \cdots & \mathrm{A}_{1, \mathrm{~d}} \\
\vdots & \ddots & \vdots \\
\mathrm{A}_{\mathrm{n}, 1} & \cdots & \mathrm{A}_{\mathrm{n}, \mathrm{d}}
\end{array}\right]
$$

Where $M_{\text {Ant }}$; is the matrix for each position's ant, $A_{i j}$; presents the value of $j_{\text {th }}$ variable of $i_{\text {th }}$ ant, $n$; is the number of variables, antlion's position is presented with:

$$
\mathrm{M}_{\text {Antlion }}=\left[\begin{array}{ccc}
\mathrm{AL}_{1,1} & \cdots & \mathrm{AL}_{1, \mathrm{~d}} \\
\vdots & \ddots & \vdots \\
\mathrm{AL}_{\mathrm{n}, 1} & \cdots & \mathrm{AL}_{\mathrm{n}, \mathrm{d}}
\end{array}\right]
$$

Where $\mathrm{M}_{\text {Antlion }}$; is the matrix for each antlion position, $A L_{i j}$; presents the value of $j_{\text {th }}$ variable of $i_{\text {th }}$ antlion, $n$; is the antlion's number, $\mathrm{d}$; is the number of variables.

Eqs. (11)-(13) are used to keep the randomly walks.

$$
\begin{aligned}
& X_{i}^{t}(t)=\frac{\left(X_{i}\left(t_{c i}\right)-a_{i}\right) *\left(d_{i}-c_{i}\left(t_{c i}\right)\right)}{\left(X_{i}\left(t_{c i}\right)-a_{i}\right)}+C_{i} \\
& C_{j}\left(t_{c i}\right)=\text { Antlion }_{j}\left(t_{c i}\right)+C\left(t_{c i}\right) \\
& d_{j}\left(t_{c i}\right)=\text { Antlion }_{j}\left(t_{c i}\right)+d\left(t_{c i}\right)
\end{aligned}
$$

Where $\mathrm{a}_{\mathrm{i}}$; is the minimum of random walk of $\mathrm{i}_{\mathrm{th}}$ variable, $\mathrm{d}_{\mathrm{i}}$; is the maximum of random walk in $\mathrm{i}_{\mathrm{th}}$ variable, $\mathrm{c}_{\mathrm{i}}\left(\mathrm{t}_{\mathrm{ci}}\right)$; is the minimum of $\mathrm{i}_{\mathrm{th}}$ variable at th iteration, $\mathrm{d}_{\mathrm{i}}\left(\mathrm{t}_{\mathrm{ci}}\right)$; is the maximum of ith variable at th iteration, $\mathrm{C}(\mathrm{t})$; is the minimum of all variables at $\mathrm{t}_{\mathrm{th}}$ iteration, $\mathrm{d}\left(\mathrm{t}_{\mathrm{ci}}\right)$; indicated the vector including the maximum of all variables at th iteration, $\mathrm{C}_{\mathrm{j}}\left(\mathrm{t}_{\mathrm{ci}}\right)$; is the minimum of all variables for $\mathrm{i}_{\mathrm{th}}$ ant, $\mathrm{d}_{\mathrm{j}}\left(\mathrm{t}_{\mathrm{ci}}\right)$; is the maximum of all variables for $i_{\text {th }}$ ant, Antlion ${ }_{j}$; shows the position of the selected $\mathrm{j}$-antlion at $\mathrm{t}_{\mathrm{th}}$ iteration.

After catching a solution, the proposed method try to catch another one, Eq. (14) represent another catching process.

$$
\begin{aligned}
\operatorname{Antlion}_{\mathrm{j}}\left(\mathrm{t}_{\mathrm{ci}}\right)=\operatorname{Ant}_{\mathrm{i}}\left(\mathrm{t}_{\mathrm{ci}}\right) & \text { if } \mathrm{f}\left(\operatorname{Ant}_{\mathrm{i}}\left(\mathrm{t}_{\mathrm{ci}}\right)\right) \\
& >f
\end{aligned}
$$

Where $t_{c i}$; shows the current iteration, Antlion $_{j}\left(t_{c i}\right)$; is the position of selected $\mathrm{j}$-antlion at $\mathrm{t}_{\mathrm{th}}$ iteration, $\mathrm{Ant}_{\mathrm{i}}\left(\mathrm{t}_{\mathrm{ci}}\right)$; indicates the position of $i_{\text {th }}$ ant at $t_{\text {th }}$ iteration.

The last stage of the method is the selectivity phase; means how to choose the best solution, Eq. (15) represent this stage.

$$
\operatorname{Ant}_{\mathrm{i}}\left(\mathrm{t}_{\mathrm{ci}}\right)=\frac{\mathrm{R}_{\mathrm{A}}\left(\mathrm{t}_{\mathrm{ci}}\right)+\mathrm{R}_{\mathrm{E}}\left(\mathrm{t}_{\mathrm{ci}}\right)}{2}
$$

Where $R_{A}\left(t_{c i}\right)$; is the random walk around the antlion selected by the roulette wheel at $t_{t h}$ iteration, $R_{E}\left(t_{c i}\right)$; is the random walk around the elite at th iteration, $\operatorname{Ant}_{\mathrm{i}}\left(\mathrm{t}_{\mathrm{ci}}\right)$; indicates the position of $\mathrm{i}_{\mathrm{th}}$ ant at th iteration.

\section{OBJECTIVE FUNCTION \& CONSTRAINTS}

In our proposed method, the total active power losses (TPL) minimization, and the total voltage stability index (TVSI) maximization are taken into consideration as individual objectives, and calculated as:

$$
\begin{gathered}
\mathrm{TPL}=\sum_{\mathrm{i}=1}^{\mathrm{N}-1} \sum_{\mathrm{j}=2}^{\mathrm{N}} \mathrm{Pl}_{\mathrm{ij}} \begin{array}{r}
\mathrm{i}=1,2, \ldots, \mathrm{N}-1 \\
\mathrm{j}=2,3, \ldots, \mathrm{N}
\end{array} \\
\mathrm{P}_{\mathrm{eff}, \mathrm{j}}=\frac{\left|\mathrm{V}_{\mathrm{i}}\right|\left|\mathrm{V}_{\mathrm{j}}\right|}{\left|\mathrm{Z}_{\mathrm{ij}}\right|} \cos \left(\varphi_{\mathrm{ij}}-\delta_{\mathrm{i}}+\delta_{\mathrm{j}}\right) \\
-\frac{\left|\mathrm{V}_{\mathrm{j}}\right|^{2}}{\left|\mathrm{Z}_{\mathrm{ij}}\right|^{2}} \cos \left(\varphi_{\mathrm{ij}}\right) \\
\mathrm{Q}_{\mathrm{eff}, \mathrm{j}}=\frac{\mathrm{V}_{\mathrm{i}}|| \mathrm{V}_{\mathrm{j}} \mid}{\left|\mathrm{Z}_{\mathrm{ij}}\right|^{2}} \sin \left(\varphi_{\mathrm{ij}}-\delta_{\mathrm{i}}+\delta_{\mathrm{j}}\right) \\
-\frac{\left|\mathrm{V}_{\mathrm{j}}\right|^{2}}{\left|\mathrm{Z}_{\mathrm{ij}}\right|^{2}} \sin \left(\varphi_{\mathrm{ij}}\right)
\end{gathered}
$$

Where $\mathrm{Pl}_{\mathrm{ij}}$; is the branch current $\mathrm{i}-\mathrm{j}, \mathrm{P}_{\mathrm{eff}, \mathrm{j}}$ and $\mathrm{Q}_{\mathrm{eff}, \mathrm{j}}$; are the effective active and reactive power fed bus $\mathrm{j}, \mathrm{Z}_{\mathrm{ij}}$ and $\varphi_{\mathrm{ij}}$; are the line impedance and angle of line $i-j$, respectively, $\delta_{i}$ and $\delta_{j}$; are the angles of $\left|V_{i}\right|$ and $\left|V_{j}\right|$, respectively. The voltage stability index is given by [1]:

$$
\begin{aligned}
& V_{\text {SI }}=\left|V_{i}\right| 4- 4 \times\left(P_{e f f, j} \times R_{i j}+Q_{e f f, j} \times X_{i j}\right) \\
& \times\left|V_{i}\right|^{2}-4 \\
& \times\left(\left(P-P_{e f f, j}\right) \times X_{i j}+\left(Q-Q_{e f f, j}\right)\right. \\
&\left.\times R_{i j}\right)^{2} \\
& \text { TVSI }=\sum_{j=2}^{N} V_{j} \quad j=2,3, \ldots, N
\end{aligned}
$$

The loss sensitivity factor (LSF) is [1]: 
TABLE I. ADJUSTED PARAMETERS OF THE CONSTRAINTS.

$$
\begin{gathered}
\mathrm{LSF}_{\mathrm{ij}}=\frac{\partial \mathrm{P}_{\mathrm{ij}-\mathrm{loss}}}{\partial \mathrm{P}_{\text {eff }, \mathrm{j}}}=\frac{2 \mathrm{P}_{\text {eff }, \mathrm{j}}}{\left|\mathrm{V}_{\mathrm{j}}\right|^{2}} * \mathrm{R}_{\mathrm{ij}} \quad \begin{array}{r}
\mathrm{j}=2,3, \ldots, \mathrm{N} \\
\mathrm{i}=1,2, \ldots, \mathrm{N}-1
\end{array} \\
\mathrm{LSF}(\mathrm{j})=\frac{\mathrm{LSF}_{\mathrm{ij}}-\mathrm{LSF}_{\text {min }}}{\mathrm{LSF}_{\text {max }}-\mathrm{LSF}_{\text {min }}} \quad \mathrm{j}=2,3, \ldots, \mathrm{N}
\end{gathered}
$$

Where $\operatorname{LSF}(\mathrm{j})$; is the value of LSF of bus $\mathrm{j}$, LSFmax and LSFmin; are the maximum and minimum values of LSFs, respectively,

The total active power loss reductions percentage (LD\%) is calculate by Eq. (24).

$$
\mathrm{LD} \%=\frac{\mathrm{TPL}_{\mathrm{woDG}}-\mathrm{TPL}_{\mathrm{wDG}}}{\mathrm{TPL}_{\mathrm{WoDG}}} * 100
$$

Where $\mathrm{TPL}_{\mathrm{wDG}}$ and $\mathrm{TPL}_{\mathrm{woDG}}$; active power with DG and without DG, respectively.

The respected inequality constraints are:

$$
\begin{aligned}
& \mathrm{P}_{\mathrm{DG}, \mathrm{i}}^{\mathrm{Min}} \leq \mathrm{P}_{\mathrm{DG}, \mathrm{i}} \leq \mathrm{P}_{\mathrm{DG}, \mathrm{i}}^{\mathrm{Max}}=1, \mathrm{i} \mathrm{N}_{\mathrm{DG}} \\
& \mathrm{Q}_{\mathrm{DG}, \mathrm{i}}^{\mathrm{Min}} \leq \mathrm{Q}_{\mathrm{DG}, \mathrm{i}} \leq \mathrm{Q}_{\mathrm{DG}, \mathrm{i}}^{\mathrm{Max}}=\underset{1,2, \ldots \ldots, \mathrm{N}_{\mathrm{DG}}}{\mathrm{i}} \\
& \leq\left|\mathrm{V}^{\operatorname{Max}}\right| \leq\left|\mathrm{V}_{\mathrm{i}}\right| \quad=1,2, \ldots \ldots, \mathrm{N} \\
& \left|S_{i}\right| \leq\left|S_{i}^{\text {rated }}\right|=1,2, \ldots \ldots, n b r \\
& \sum_{i=1}^{N_{D G}} P_{D G} \leq \mu \sum_{j=1}^{N_{L}} P_{D, j} \\
& \text { TPL }\left.\right|_{\text {W-DG }}<\text { TPL }\left.\right|_{\text {WO-DG }}
\end{aligned}
$$

TQL $\left.\right|_{\text {W-DG }}<$ TQL $\left.\right|_{\text {WO-DG }}$

Where $P_{D G, i}^{M i n}, P_{D G, i}^{M a x}, Q_{D G, i}^{M i n}$ and $Q_{D G, i}^{M a x}$; are the lower and higher limits of active and reactive output power of DG unit, respectively, $\mathrm{N}_{\mathrm{DG}}$; is the number of DGs, $\mathrm{V}^{\mathrm{Min}}, \mathrm{V}^{\mathrm{Max}}$; minimum and maximum allowed bus voltage, $S_{i}^{\text {rated }}$; the rated VA of branch $i, \mu$; is the maximum penetration level, $\mathrm{N}_{\mathrm{L}}$; is the number of connected loads, TPL $\left.\right|_{\text {W-DG }},\left.\mathrm{TPL}\right|_{\text {wo- }}$ ${ }_{\mathrm{DG}},\left.\mathrm{T}_{\mathrm{QL}}\right|_{\text {W-DG }}$ and $\left.\mathrm{T}_{\mathrm{QL}}\right|_{\text {wO-DG}}$; are the total active and reactive power loss with and without DGs, respectively. Inequality constraints on the three studied systems are listed in Table. I.

\begin{tabular}{|c|l|l|l|}
\hline \multirow{2}{*}{ Parameter } & \multicolumn{3}{|c|}{ Set value(s) } \\
\cline { 2 - 4 } & \multicolumn{1}{|c|}{ 33-node } & 69-node & 118-node \\
\hline $\begin{array}{c}\text { Max- } \\
\text { Iterations }\end{array}$ & 500 & 500 & 500 \\
\hline $\begin{array}{c}\mu \\
\text { (Penetration } \\
\text { Level) }\end{array}$ & $50 \%$ & $50 \%$ & $50 \%$ \\
\hline $\begin{array}{c}\text { Voltage } \\
\text { limits }\end{array}$ & $92 \% \leq|\mathrm{Vi}| \leq 110 \%$ & $92 \% \leq|\mathrm{Vi}| \leq 110 \%$ & $86.5 \% \leq|\mathrm{Vi}| \leq 110 \%$ \\
\hline $\begin{array}{c}\text { Active } \\
\text { power limit } \\
\text { of a DG }\end{array}$ & $0 \leq \mathrm{P}_{\mathrm{DG}} \leq 5 \mathrm{MW}$ \\
\hline $\begin{array}{c}\text { Reactive } \\
\text { power limit } \\
\text { of DG }\end{array}$ & $\mathrm{Q}_{\mathrm{DG}}=0$ for type-1 DG \\
\cline { 2 - 4 } & $0 \leq \mathrm{Q}_{\mathrm{DG}} \leq 4 \mathrm{MV}$ ar for type-2 DG \\
\cline { 2 - 3 } & $Q_{D G}=-\left(0.05+0.04 P_{D G}^{2}\right)$ for type-3 DG \\
\hline
\end{tabular}

\section{RESULTS AND DISCUSSION}

Initial load flow results for the 33-node, 69-node and 118node systems shown in Fig. 2 (a)-(c) are tabulated in Table II, it found that from the table minimum bus voltages are 0.9134 p.u (at bus 18), 0.9102 (at bus 65) and 0.8654 at 118 for 33, 69 and 118_bus system, respectively, and total power losses are $201.89(\mathrm{~kW}), 224.59(\mathrm{~kW})$ and $1294.3(\mathrm{~kW})$ for 33, 69 and 118_bus system, respectively, total voltage deviations are 1.696, 1.824 and 5.92 (p.u) for 33, 69 and 118_bus system, respectively, total voltage stability indexes are 25.86, 62.25 and 95.84 for 33, 69 and 118_bus system, respectively, and the cost of losses are 106114.96, 118046.34 and $680284.08 \$$ per year along with the annual cost of system losses considering $0.06 \$$ per $\mathrm{kW}$ [22] for 33, 69 and 118_bus system, respectively. Two cases study are considered in this paper, the first is using only one DG unit, and the second is dealing with installing two DGs. Fig 3 is a flow chart for proposed method.

In the first case study and at TPL objective, the effectiveness of installing one DG units in the 33, 69, 118node RDNs is investigated, cropped results are listed in Table III. In case one which used one DG For 33-node system, the active power loss decreased from $201.89 \mathrm{~kW}$ to $109.16,67.6$ and 120.05 in case of Type-1, 2 and 3, respectively.

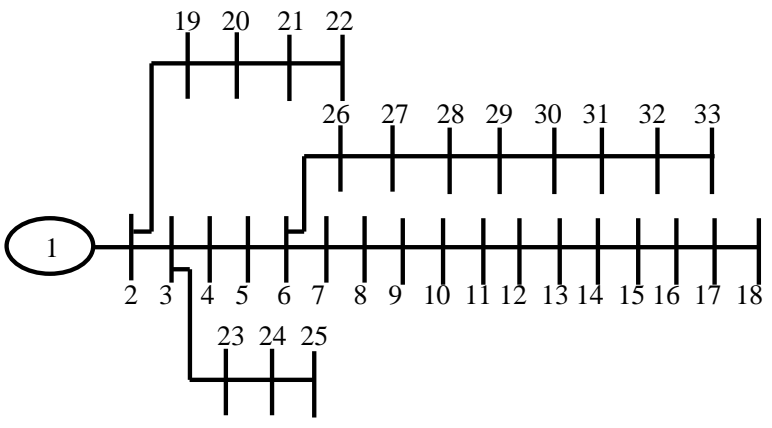

Figure 2(a). Single line diagram of the 33-node RDN 


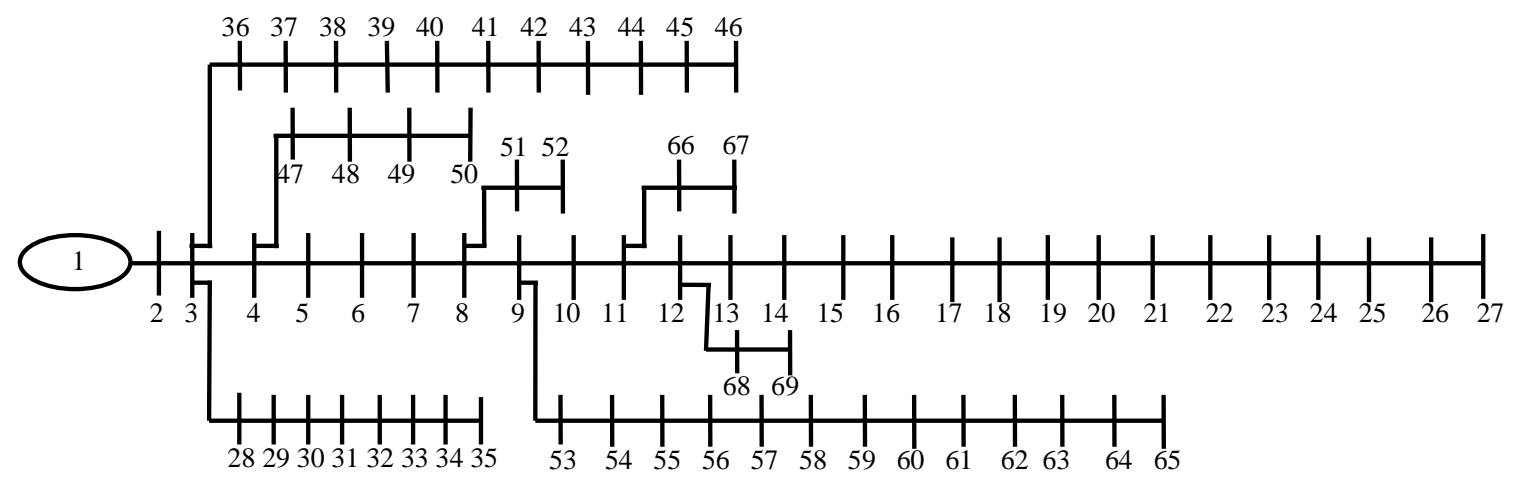

Figure 2(b). Single line diagram of the 69 -node RDN

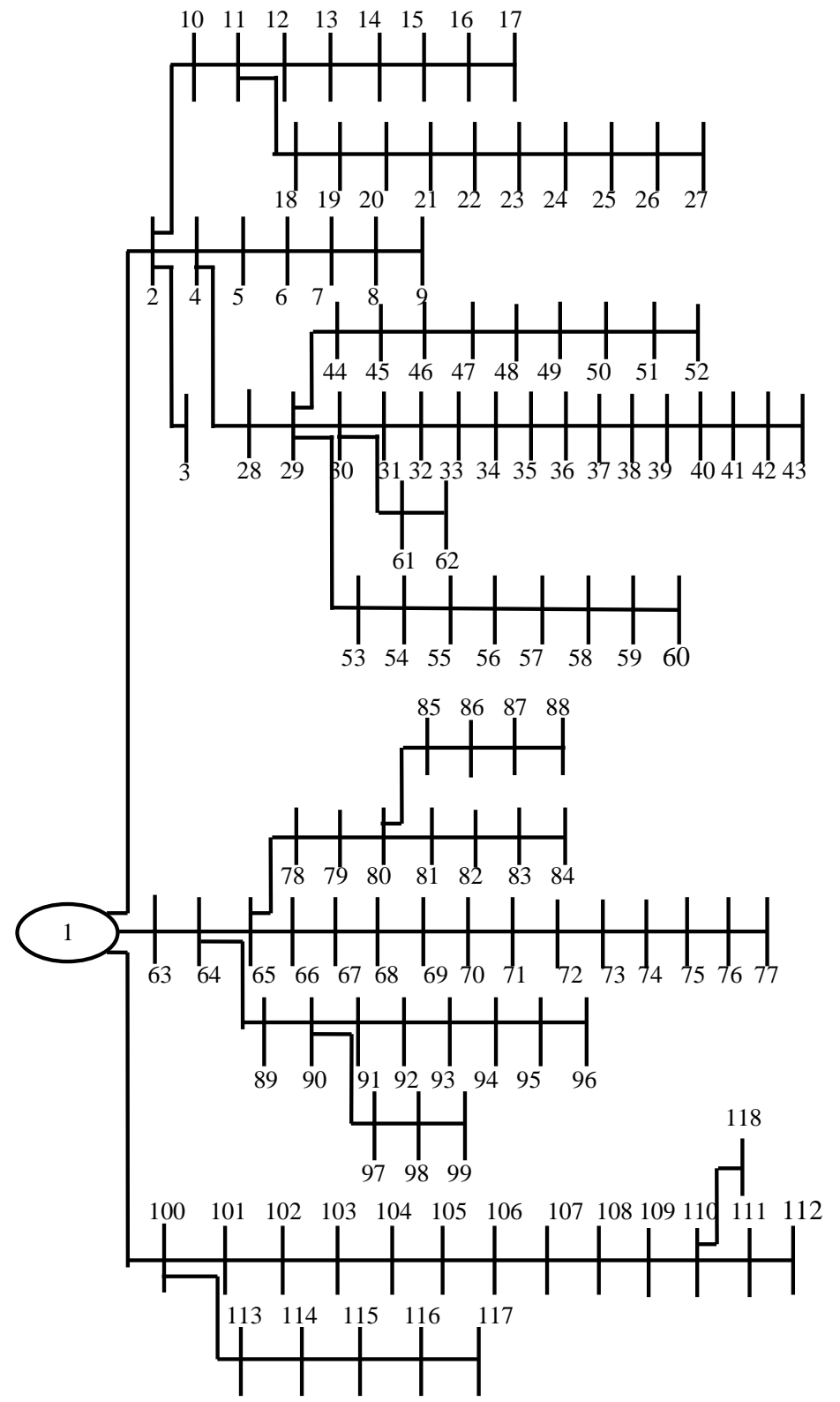

Figure 2(c). Single line diagram of the 118-node RDN
TABLE II. INITIAL LF RESULTS IN THE BASE CASE (WITHOUT DG),

\begin{tabular}{|c|l|l|l|}
\hline Item & 33-node RDN & \multicolumn{1}{|c|}{ 69-node RDN } & 118-node RDN \\
\hline $\begin{array}{c}\text { Vmin } \\
\text { (p.u) }\end{array}$ & 0.9134 at 18 & 0.9102 at 65 & 0.8654 at 118 \\
\hline $\begin{array}{c}\text { Vmax } \\
\text { (p.u) }\end{array}$ & 0.9970 at 2 & 1 at 2 & 0.997 at 2 \\
\hline $\begin{array}{c}\text { TVD } \\
\text { (p.u) }\end{array}$ & 1.6960 & 1.8236 & 5.9212 \\
\hline VSI $_{\min }$ & 0.6960 at 18 & 0.6863 at 65 & 0.5527 at 118 \\
\hline VSI $_{\max }$ & 0.9882 at 2 & 0.9999 at 2 & 0.9878 at 3 \\
\hline TVSI & 25.8634 & 61.2524 & 95.8434 \\
\hline $\begin{array}{c}\text { TPL } \\
(\text { KW) }\end{array}$ & 201.893 & 224.5935 & 1294.3 \\
\hline $\begin{array}{c}\text { TQL } \\
(\text { KW) }\end{array}$ & 134.6413 & 101.9903 & 1033.2 \\
\hline $\begin{array}{c}\text { Total load } \\
\text { (MVA) }\end{array}$ & $3.72+\mathrm{j} 2.3$ & $3.8021+\mathrm{j} 2.6946$ & $22.710+\mathrm{j} 17.041$ \\
\hline $\begin{array}{c}\text { Cost of } \\
\text { losses(\$/year }\end{array}$ & 106114.96 & 118046.34 & 680284.08 \\
\hline
\end{tabular}

The lowest voltage of the system improved from 0.9134 p.u. at bus- 18 to 0.9456 at bus $33,0.9576$ at bus 18 and 0.9399 at bus-18 in case of Type-1, 2 and 3, respectively. Cost of losses reduced from 106114.96 (\$/year) to $57371.9,35532.71$ and 63096.55 in case of Type-1, 2 and 3, respectively. Saving cost due to installing DG was 48743.1 (\$/year), 70582.2543018 .42 in case of Type-1, 2 and 3, respectively. The DG running costs are 41418.56, 82598.75 and 72884.5 \$ per year. By comparing Cost of losses, DG running cost and Saving cost we get the net saving cost, which equal 18983.1, 10132.25 and 17431.5 in case of Type-1, 2 and 3, respectively. The negative value for nest saving cost means the running cost of DG is very high and this case is undesirable.

In case of using one DG For 69-node system, the active power loss decreased from $224.5935 \mathrm{~kW}$ to 81.5391 , 23.1701 and 98.9934 in case of Type-1, 2 and 3, respectively. The lowest voltage of the system improved from 0.9102 p.u. at bus-65 to 0.9693 at bus-27, 0.9726at bus-26,27 and 0.9677 at bus-27, respectively. Cost of losses reduced from 118046.34 (\$/year) to 42856.95 , 12178.14 and 52030.93 in case of Type-1, 2 and 3, 
respectively. Saving cost was $75189.39,105868.14$ and 66015.41 (\$/year) in case of Type-1, 2 and 3, respectively. The DG running costs are 30223.68, 59384 and 55422.25 $\$$ per year. The net saving cost are equal 44965.7, 46484.14 and -10593.16 (\$/year) in case of Type-1, 2 and 3 , respectively. From the net saving costs values for three types we notice that all values are positive that means all types of DGs are desirable and type-2 are favorite .

In case of using one DG for 118-node system, the active power loss decreased from $1294.3 \mathrm{~kW}$ to 1082.7 , 1008.9, and $1113.2 \mathrm{~kW}$ in case of DG type-1, 2 and 3, respectively. The lowest voltages of the system improved from 0.8654 p.u. at bus- 118 to $0.87,0.9722$ and 0.868 at bus-118, respectively. The cost of losses reduced from 680284.08 (\$/year) to $569067.12,530277.84$ and 585097.92 in case of Type-1, 2 and 3, respectively. Saving cost was $111216.96,150006.24$ and 95186.16 (\$/year) in case of Type-1, 2 and 3, respectively. The DG running costs are $45908.8,90632.75$ and $80424.5 \$$ per year. The net saving cost are 65308.16, 59373.49 and 14761.66 (\$/year) in case of Type-1, 2 and 3, respectively.

At TVSI objective, The highest voltage of the 33-bus system improved from 0.997 p.u. at bus-2 to 0.9982 p.u. at bus-2, 1.0385 p.u. at bus-11 and 0.9982 p.u. at bus-33, with DG type 1, 2 and 3, respectively. The lowest voltage of the 33-bus system improved to 0.9458 p.u. at bus-2, 0.9618 p.u. at bus- 11 and 0.9444 p.u. at bus-33, with DG type 1,2 and 3 , respectively. The active power loss decreased to $122.41,126.42$ and 134.94 in case of Type-1, 2 and 3, respectively. The net saving costs were 12017.8, 20748.68 and -25260.9 \$ per year in case of Type-1, 2 and 3 , respectively.

For 69-bus system, the highest voltages improved from 1 p.u. at bus- 2 to 1.01 p.u. at bus-61 with DG type 2, and is 1 at bus-2 with DG type 1 and 3, respectively. The lowest voltages improved to 0.9694 p.u. at bus-2, 0.9751 p.u. at bus-26,27 and 0.9689 p.u. at bus-27, with DG type 1,2 and 3, respectively. The active power loss decreased to $81.5441,104.38$ and 100.51 in case of Type-1, 2 and 3, respectively. The net saving costs were 44769.96, 18650.7 and 3438.05 \$ per year in case of Type-1, 2 and 3, respectively.

For 118-bus system, The highest voltages improved from 0.997 p.u. at bus-2 to 1 p.u. at bus- 72 with DG type 2 , and is fixed at bus-2 with DG type 1 and 3, respectively. The lowest voltages improved to 0.87 p.u. at bus- 118 , 0.8749 p.u. and 0.87 p.u. at bus-118, with DG type 1,2 and 3, respectively. The active power loss decreased to 1093.4, 1050 and 1234.5 in case of Type-1, 2 and 3, respectively. The net saving costs were 48393.04, 26075.88 and -119197 \$ per year in case of Type-1, 2 and 3 , respectively.

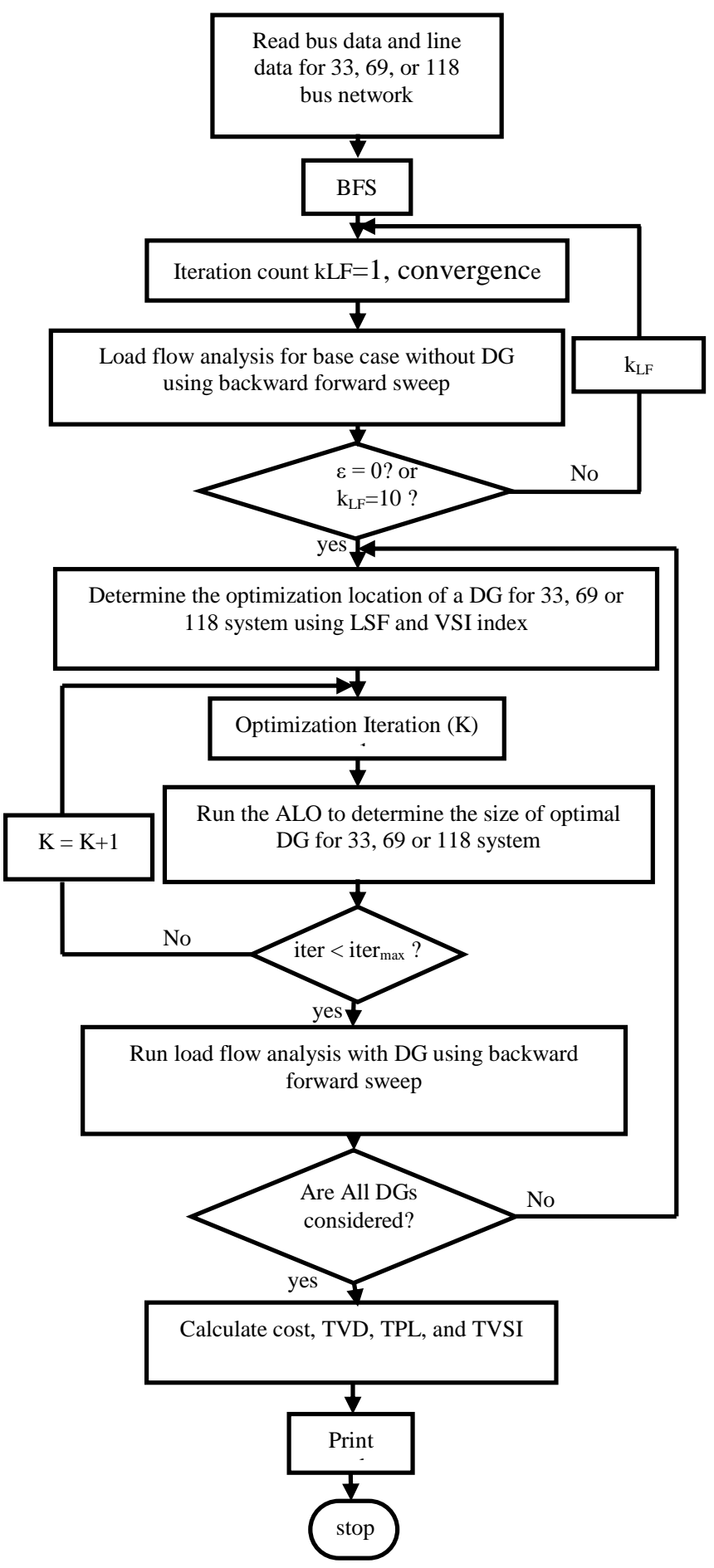

Figure 3. flow chart of proposed method

The networks voltage profiles without and with DG units of types 1, 2 and 3 are shown in Fig. 4 (a)-(f) for TPL and TVSI, respectively. With type-2 (injecting both active and reactive power), voltage profile is the best among other DGs types and the TVSI is the highest. 
TABLE III. CROPPED RESULTS AFTER EMPLOYING ONE DG FOR 33, 69 AND118-NODE SYSTEMS (BEST OUT OF 50 RUNS)

\begin{tabular}{|c|c|c|c|c|c|c|c|c|c|c|}
\hline \multirow{2}{*}{\multicolumn{2}{|c|}{$\begin{array}{c}\text { System } \\
\text { DG Type }\end{array}$}} & \multicolumn{3}{|c|}{ 33-node system } & \multicolumn{3}{|c|}{ 69-node system } & \multicolumn{3}{|c|}{ 118-node system } \\
\hline & & 1 & 2 & 3 & 1 & 2 & 3 & 1 & 2 & 3 \\
\hline \multirow{8}{*}{ 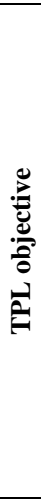 } & $\begin{array}{c}\text { DG size } \\
\text { (MVA) }\end{array}$ & $\begin{array}{l}1.860 \\
\text { at } 8\end{array}$ & $\begin{array}{l}(1.860+ \\
\mathrm{j} 1.7484) \\
\text { at } 6\end{array}$ & $\begin{array}{l}(1.86- \\
\text { j0.1884) } \\
\text { at } 6\end{array}$ & $\begin{array}{l}1.8889 \\
\text { at } 61\end{array}$ & $\begin{array}{l}(1.8272+ \\
\mathrm{j} 1.3024) \\
\text { at } 61\end{array}$ & $\begin{array}{l}(1.7053- \\
j 0.1663) \\
\text { at } 61\end{array}$ & $\begin{array}{l}2.8693 \\
\text { at } 72\end{array}$ & $\begin{array}{l}(2.7887+ \\
\mathrm{j} 1.8251) \\
\text { at } 72\end{array}$ & $\begin{array}{l}(2.4746- \\
j 0.2949) \\
\text { at } 72\end{array}$ \\
\hline & Vmin (p.u) & $\begin{array}{l}0.9456 \\
\text { at } 33\end{array}$ & $\begin{array}{l}0.9576 \\
\text { at } 18\end{array}$ & $\begin{array}{l}0.9399 \\
\text { at } 18\end{array}$ & $\begin{array}{l}0.9693 \\
\text { at } 27\end{array}$ & $\begin{array}{l}0.9726 \\
\text { at } 26,27\end{array}$ & $\begin{array}{l}0.9677 \\
\text { at } 27\end{array}$ & $\begin{array}{l}0.8691 \\
\text { at } 118\end{array}$ & $\begin{array}{l}0.8722 \\
\text { at } 118 \\
\end{array}$ & $\begin{array}{l}0.8681 \\
\text { at } 118\end{array}$ \\
\hline & $V \max (p . u)$ & $\begin{array}{l}0.9982 \\
\text { at } 2\end{array}$ & $\begin{array}{l}0.9987 \\
\text { at } 2\end{array}$ & $\begin{array}{l}0.9982 \\
\text { at } 2\end{array}$ & 1 at 2 & $\begin{array}{l}1 \\
\text { at } \\
2,3,28,36\end{array}$ & 1 at 2 & $\begin{array}{l}0.997 \\
\text { at } 2\end{array}$ & $\begin{array}{l}0.997 \\
\text { at } 2\end{array}$ & $\begin{array}{l}0.997 \\
\text { at } 2\end{array}$ \\
\hline & TVSI & 28.549 & 29.3590 & 27.9557 & 64.883 & 65.7255 & 64.4288 & 98.548 & 99.6477 & 97.9921 \\
\hline & TPL (KW) & 109.16 & 67.6041 & 120.046 & 81.539 & 23.1701 & 98.9934 & 1082.7 & 1008.9 & 1113.2 \\
\hline & TQL (KW) & 75.091 & 51.5672 & 84.2249 & 39.671 & 14.3783 & 47.3295 & 880.07 & 826.5636 & 934.293 \\
\hline & Loss red. & $45.93 \%$ & $66.51 \%$ & $40.54 \%$ & $63.69 \%$ & $89.684 \%$ & $55.92 \%$ & $16.35 \%$ & $22.05 \%$ & $13.99 \%$ \\
\hline & $\begin{array}{c}\text { Net saving } \\
\text { cost } \\
(\$ / \text { year })\end{array}$ & 18983.1 & 10132.25 & -17431.5 & 44965.7 & 46484.14 & 10593.16 & 65308.16 & 59373.49 & 14761.66 \\
\hline \multirow{8}{*}{ 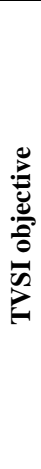 } & $\begin{array}{c}\text { DG size } \\
\text { (MVA) }\end{array}$ & $\begin{array}{l}1.86 \\
\text { at } 11\end{array}$ & $\begin{array}{l}(1.859+\mathrm{j} 1.96 \\
6) \\
\text { at } 11\end{array}$ & $\begin{array}{l}(1.86- \\
\mathrm{j} 0.1884) \\
\text { at } 11\end{array}$ & $\begin{array}{l}1.90105 \\
\text { at } 61\end{array}$ & $\begin{array}{l}(1.37026+\mathrm{j} \\
2.809) \\
\text { at } 61\end{array}$ & $\begin{array}{l}(1.901- \\
j 0.1946) \\
\text { at } 61\end{array}$ & $\begin{array}{l}(3.575) \\
\text { at } 72\end{array}$ & $\begin{array}{l}(3.14856+ \\
j 3.20526) \\
\text { at } 72\end{array}$ & $\begin{array}{l}(4.6347- \\
\mathrm{j} 0.9092) \\
\text { at } 72\end{array}$ \\
\hline & Vmin (p.u) & $\begin{array}{l}0.9458 \\
\text { at } 33\end{array}$ & $\begin{array}{l}0.9618 \\
\text { at } 33\end{array}$ & $\begin{array}{l}0.9444 \\
\text { at } 33\end{array}$ & $\begin{array}{l}0.9694 \\
\text { at } 26,27\end{array}$ & $\begin{array}{l}0.9751 \\
\text { at } 26,27\end{array}$ & $\begin{array}{l}0.9689 \\
\text { at } 27\end{array}$ & $\begin{array}{l}0.87 \\
\text { at } 118\end{array}$ & $\begin{array}{l}0.8749 \\
\text { at } 118 \\
\end{array}$ & $\begin{array}{l}0.87 \\
\text { at } 118 \\
\end{array}$ \\
\hline & $V \max (p . u)$ & $\begin{array}{l}0.9982 \\
\text { at } 2\end{array}$ & $\begin{array}{l}1.0385 \\
\text { at } 11\end{array}$ & $\begin{array}{l}0.9982 \\
\text { at } 2\end{array}$ & 1at 2 & $\begin{array}{l}1.01 \\
\text { at } 61\end{array}$ & 1 at 2 & $\begin{array}{l}0.997 \\
\text { at } 2\end{array}$ & $\begin{array}{l}1 \\
\text { at } 72\end{array}$ & $\begin{array}{l}0.997 \\
\text { at } 2\end{array}$ \\
\hline & TVSI & 29.5425 & 32.0855 & 29.3368 & 64.9060 & 66.38 & 64.7896 & 99.2353 & 100.9579 & 99.8127 \\
\hline & TPL $(\mathrm{KW})$ & 122.407 & 126.4196 & 134.9427 & 81.5441 & 104.38 & 100.5057 & 1093.4 & 1050 & 1234.5 \\
\hline & TQL (KW) & 83.9066 & 91.0981 & 92.4166 & 39.6533 & 46.89 & 47.7490 & 879.8424 & 839.3735 & 957.7734 \\
\hline & Loss red. & $39.37 \%$ & $37.38 \%$ & $33.16 \%$ & $63.69 \%$ & $53.52 \%$ & $55.25 \%$ & $15.52 \%$ & $18.88 \%$ & $4.62 \%$ \\
\hline & $\begin{array}{c}\text { Net saving } \\
\text { cost } \\
\text { (\$/year) }\end{array}$ & 12017.8 & -20748.68 & -25260.9 & 44769.96 & 18650.7 & 3438.05 & 48393.04 & 26075.88 & -119197 \\
\hline
\end{tabular}

In case of 33_node system all types of DG the DG size were maximum penetration level $(1860 \mathrm{kVA})$, for that installing DGs without penetration level should take in proposed method. The effectiveness of installing one DG unit in the 33-node RDN without limiting the penetration level is examined as given in Table IV. At TPL objective, the lowest voltage of the system improved from 0.9134 p.u. at bus- 18 to $0.9474,0.9635$ and 0.9475 p.u. at bus-33, in case of Type-1, 2 and 3, respectively,. The maximum voltage of the system improved to 0.9987 bus-2, 1.0013 at bus- 6 and 0.9984 p.u. at bus-2 in case of Type-1, 2 and 3, respectively. While the active power loss decreased to $102.79,61.31$ and $117.61 \mathrm{~kW}$ in case of Type-1, 2 and 3, respectively, less than in case of penetration level, the net saving costs were $10670.13,-8709.64$ and -28586.14 \$ per year in case of Type-1, 2 and 3, respectively, less than in case of penetration level, that is due to high DG running cost which proportion with DG rating. At TVSI objective, the lowest voltage of the system improved to 0.9474 , 0.9635 and 0.9475 p.u. at bus-33 in case of Type-1, 2 and 3 , respectively, The maximum voltage of the system improved to 1, 1.04 and 1 p.u. at bus-11 in case of Type-1, 2 and 3 , respectively.

To examine the solution quality obtained by the proposed method, the results in case of 33-bus RDS are compared to other challenging algorithms found in literature as listed in Table V. ALO in both cases of respecting the penetration level or opening this level has the best loss reduction compared to other methods. The proposed method achieve loss reduction $46 \%$, while LSF and BSA achieve loss reduction 30.5 and $44 \%$, respectively, in case of penetration level. And without penetration level, our proposed method achieve $49.1 \%$ loss reduction, while other best one achieve $47.4 \%$ only.

In the second case study, the effectiveness of installing two DG units in the 33, 69, 118-node RDNs is investigated, cropped results are listed in Table VI. From the table, in case of 33-node and TPL objective the losses reduction are 58.52, 85.71 and $51.82 \%$ in case of Type-1, 2 and 3, respectively. The lowest voltage of the system improved to 0.9681 at bus 33, 0.9799 at bus 25 and 0.9653 at bus-33 in case of Type-1, 2 and 3, respectively. The net saving cost increased to 32340.7 and 31705.23 (\$/year) in case of Type-1 and 2, respectively, and reduced to 4249.08 (\$/year) in case of Type-3.

In case of TVSI objective the losses reduction are less than the values with TPL objective and the net saving costs also less than net saving costs with TPL objective, but the maximum voltage of the system improved higher than maximum voltage with TPL objective. 


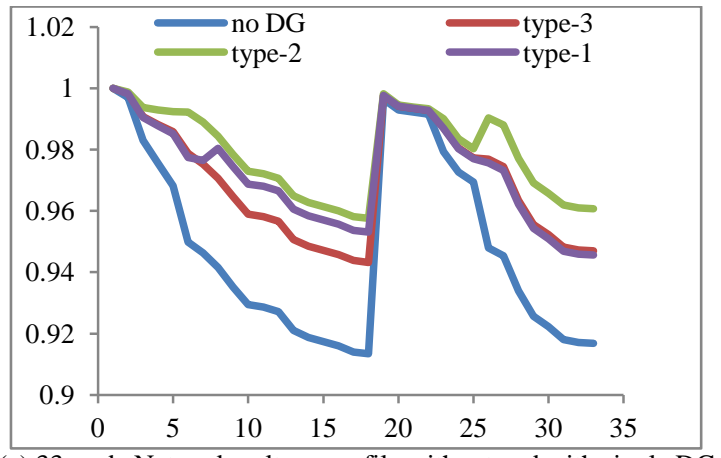

(a) 33-node Network voltage profile without and with single DG (TPL-objective)

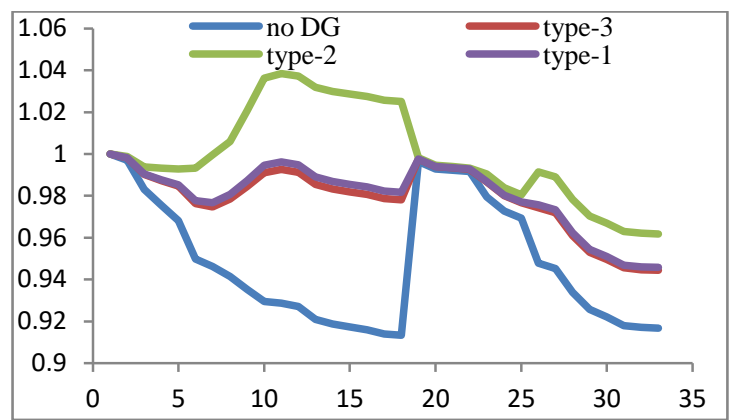

(b) 33-node Network voltage profile without and with single DG (TVSI-objective)

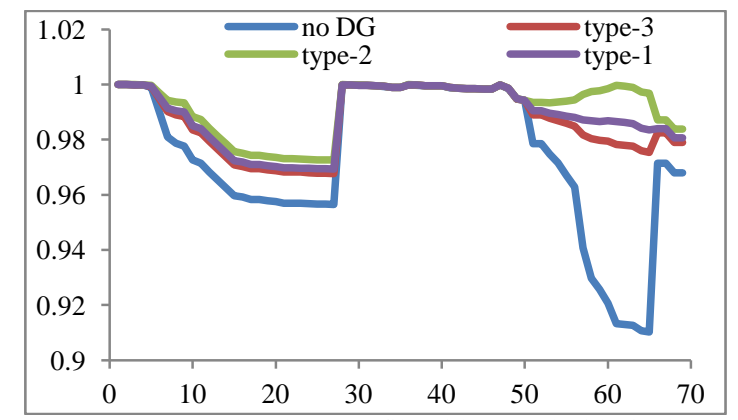

(c) 69-node Network voltage profile without and with single DG (TPL-objective)

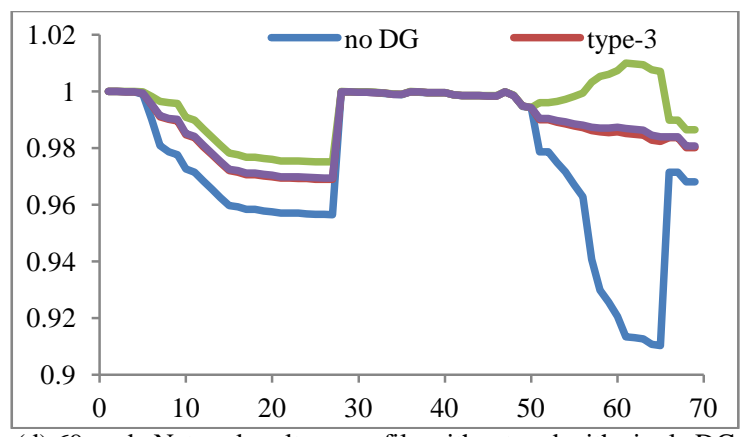

(d) 69-node Network voltage profile without and with single DG (TVSI-objective)

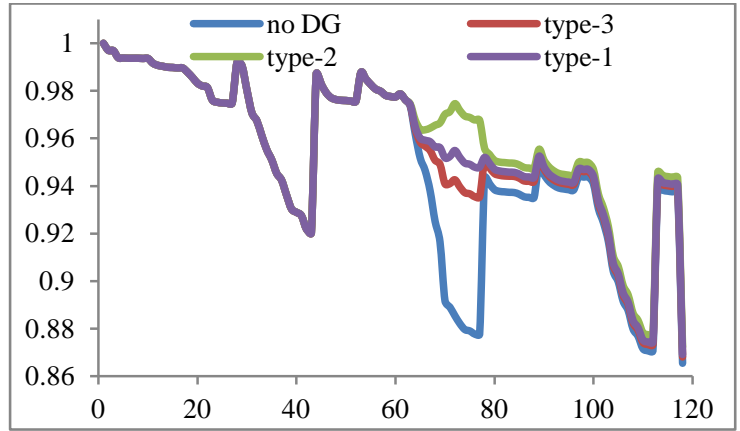

(e) 118-node Network voltage profile without and with single DG (TPL-objective)

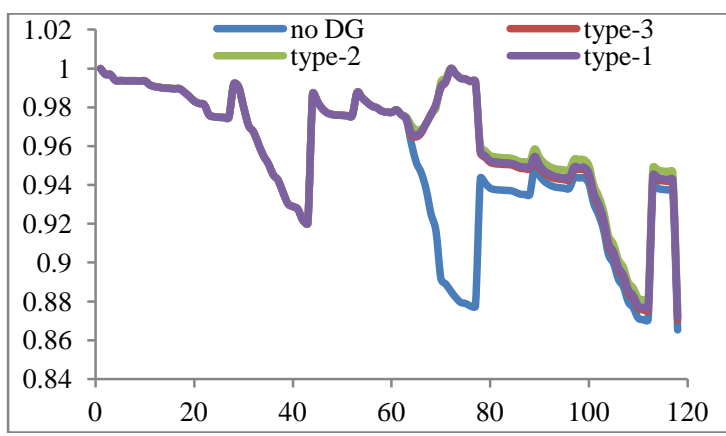

(f) 118-node Network voltage profile without and with single DG (TVSI-objective)

Figure 4. networks voltage profiles without and with DG units of types 1, 2, and 3 for TPL and TVSI

For 69-node, in case of TPL objective the losses reduction are $66.93,95.6$ and $59.46 \%$ in case of Type-1, 2 and 3 , respectively. The lowest voltage of the system improved to 0.974 at bus $65,0.9894$ at bus 65 and 0.9702 at bus-43 in case of Type-1, 2 and 3, respectively. The net saving cost increased to $15581.89,51599.27$ and 9002.48 (\$/year) in case of Type-1, 2 and 3, respectively.

In case of TVSI objective the losses reduction and the net saving costs are less than the values with TPL objective, but the maximum voltage of the system improved higher than maximum voltage with TPL objective.

For 118-node, in case of TPL objective the losses reduction are 29.84, 43.07 and $25.64 \%$ in case of Type-1, 2 and 3 , respectively. The lowest voltage of the system improved to 0.9202 at bus 43 in case of Type-1, 2 and 3 . The net saving cost increased to $110812.7,112008.05$ and 8817.65 (\$/year) in case of Type-1, 2 and 3, respectively.

In case of TVSI objective, the net saving cost in case of type- 1 is desirable and type- 2 and 3 are undesirable . 
TABLE IV. CROPPED RESULTS AFTER EMPLOYING VARIOUS TYPES OF DGS WITHOUT PENETRATION LEVEL IN 33-BUS SYSTEM (BEST OUT OF 50 RUNS)

\begin{tabular}{|c|l|l|l|l|l|l|}
\hline Item & \multicolumn{3}{|c|}{ TPL objective } & \multicolumn{1}{c|}{ TVSI objective } \\
\hline DG Type & \multicolumn{1}{|c|}{$\mathbf{2}$} & \multicolumn{1}{|c|}{$\mathbf{3}$} & \multicolumn{1}{c|}{$\mathbf{1}$} & \multicolumn{1}{c|}{$\mathbf{2}$} \\
\hline DG size (MVA) & 2.58866 at 6 & $\begin{array}{l}(2.5415+\mathrm{j} 1.7429) \\
\text { at } 6\end{array}$ & $\begin{array}{l}(2.2426-\mathrm{j} 0.2512) \\
\text { at } 6\end{array}$ & 1.9681 at 11 & $\begin{array}{l}(2.5515+\mathrm{j} 1.0703) \\
\text { at } 11\end{array}$ & $\begin{array}{l}(2.0843-\mathrm{j} 0.2238) \\
\text { at } 11\end{array}$ \\
\hline Vmin (p.u) & 0.9523 at 18 & 0.9669 at 18 & 0.9451 at 18 & 0.9474 at 33 & 0.9635 at 33 & 0.9475 at 33 \\
\hline Vmax (p.u) & 0.9987 at 2 & 1.0013 at 6 & 0.9984 at 2 & 1 at 11 & 1.04 at 11 & 1 at 11 \\
\hline TVSI & 28.9808 & 30.1681 & 28.3855 & 29.7651 & 32.2188 & 29.7662 \\
\hline TPL (KW) & 102.7897 & 61.3125 & 117.6115 & 125.1281 & 124.7344 & 143.7951 \\
\hline TQL (KW) & 74.1255 & 48.3282 & 83.1027 & 86.1595 & 89.7368 & 99.3057 \\
\hline Loss reduction & $49.09 \%$ & $69.63 \%$ & $41.7456 \%$ & $38.02 \%$ & $38.22 \%$ & $28.78 \%$ \\
\hline $\begin{array}{c}\text { Net saving cost } \\
\text { (\$/year) }\end{array}$ & 10670.13 & -8709.64 & -28586.14 & 8858.03 & -42369.19 & -37203.49 \\
\hline
\end{tabular}

TABLE V. COMPARISONS OF THE OPTIMAL RESULTS TO THE OTHER METHODS FOR 33-NODE (TPL-OBJECTIVE).

\begin{tabular}{|c|c|c|c|c|c|c|c|c|}
\hline \multicolumn{3}{|c|}{ DG type-1 } & \multicolumn{3}{|c|}{ DG type-2 } & \multicolumn{3}{|c|}{ DG type-3 } \\
\hline Method & Allocation & LD\% & Method & Allocation & LD\% & Method & Allocation & LD\% \\
\hline $\operatorname{LSF}[13]^{\mathrm{a}}$ & 0.743 at 18 & $30.5 \%$ & $\mathrm{BSA}[1]^{\mathrm{a}}$ & $(1.858+\mathrm{j} 1.895)$ at 6 & $64.6 \%$ & $\mathrm{BSA}[1]^{\mathrm{a}}$ & $(1.858-\mathrm{j} 0.188)$ at 6 & $29.6 \%$ \\
\hline $\mathrm{BSA}[1]^{\mathrm{a}}$ & 1.858 at 8 & $44 \%$ & IA [13] $]^{\mathrm{b}}$ & 3.107 with $0.82 \mathrm{PF}$ at 6 & $67.9 \%$ & $\mathrm{PSO}[31]^{\mathrm{b}}$ & $(2.216-\mathrm{j} 0.246)$ at 6 & $40.2 \%$ \\
\hline ELF [13] ${ }^{\mathrm{b}}$ & 2.600 at 6 & $47.4 \%$ & $\mathrm{IA}[13]^{\mathrm{b}}$ & 3.103 with $0.85 \mathrm{PF}$ at 6 & $67.7 \%$ & ICA $[35]^{\mathrm{b}}$ & $(2.394-j 0.279)$ at 6 & $40 \%$ \\
\hline $\mathrm{PSO}[31]^{\mathrm{b}}$ & 2.567 at 6 & $47.4 \%$ & $\mathrm{PSO}[31]^{\mathrm{b}}$ & $(2.54+\mathrm{j} 1.748)$ at 6 & $67.9 \%$ & $\mathrm{BSA}[1]^{\mathrm{b}}$ & $(2.235-\mathrm{j} 0.250)$ at 6 & $40.1 \%$ \\
\hline $\mathrm{ABC}[32]^{\mathrm{b}}$ & 3.380 at 6 & $44.8 \%$ & BSA $[1]^{\mathrm{b}}$ & $(2.559+\mathrm{j} 1.761)$ at 6 & $67.9 \%$ & $\mathrm{ALO}^{\mathrm{a}}$ & $(1.86-\mathrm{j} 0.188)$ at 6 & $40.5 \%$ \\
\hline $\mathrm{BSA}[1]^{\mathrm{b}}$ & 2.460 at 6 & $47.3 \%$ & $\mathrm{ALO}^{\mathrm{a}}$ & $(1.860+\mathrm{j} 1.7484)$ at 6 & $66.5 \%$ & $\mathrm{ALO}^{\mathrm{b}}$ & $(2.2426-\mathrm{j} 0.251)$ at 6 & $41.8 \%$ \\
\hline $\mathrm{GA}[33]^{\mathrm{b}}$ & 2.570 at 6 & $47.4 \%$ & $\mathrm{ALO}^{\mathrm{b}}$ & $(2.5415+\mathrm{j} 1.7429)$ at 6 & $69.6 \%$ & & & \\
\hline $\mathrm{ALO}^{\mathrm{a}}$ & 1.860 at 8 & $46 \%$ & & & & & & \\
\hline $\mathrm{ALO}^{\mathrm{b}}$ & 2.589 at 6 & $49.1 \%$ & & & & & & \\
\hline
\end{tabular}

a All proposed constraints are respected with $\mu=50 \%$.

b All constraints are appreciated except $\mu$.

In case of using two DGs, bus-voltage profile, total power loss reduction and net saving are better than those in the case of using one DG.

The networks voltage profile without and with two DG units of types 1,2, and 3 are shown in Figure 5(a)-(f) for TPL and TVSI, respectively, in all cases the best type of DG for improving voltage profile is type-2 DG.

The effect of opening the penetration level when installing two DGs in the 33, 69-node RDNs is listed in Table VII, more enhancement in voltage and losses are encountered but with extra cost. For 33-node, in case of TPL objective the active power losses reduced to 82.9, 28.49 and $88.72 \mathrm{~kW}$ in case of Type-1, 2 and 3 , respectively. The lowest voltage of the system improved to 0.9732 at bus-33, 0.9803 at bus-25 and 0.9688 at bus-33 in case of Type-1, 2 and 3, respectively. The net saving cost increased to 27323.55 and 27973.35 (\$ per year) in case of Type-1 and 2, respectively. In case of TVSI objective the active power losses reduced to $96.745,73.79$ and
$124.03 \mathrm{~kW}$ in case of Type-1, 2 and 3, respectively. The lowest voltage of the system improved to $0.9809,0.9858$ and 0.981 at bus-25 in case of Type-1, 2 and 3, respectively. The net saving cost was 10570.27 (\$ per year) in case of Type- 1 .

For 69-node, in case of TPL objective the active power losses reduced to $70.4557,7.2038$ and $78.754 \mathrm{~kW}$ in case of Type-1, 2 and 3, respectively. The lowest voltage of the system improved to 0.9835 at bus-65, 0.9943 at bus- 50 and 0.9831 at bus- 65 in case of Type- 1,2 and 3 , respectively. The net saving cost increased to $34067.63,41716.25$ and 3473.73 (\$ per year) in case of Type-1, 2 and 3, respectively. In case of TVSI objective the active power losses reduced to $72.3,12.55$ and 82.55 $\mathrm{kW}$ in case of Type-1, 2 and 3, respectively. The lowest voltage of the system improved to 0.9884 at bus-65, 0.9942 at bus-68 and 69 and 0.9878 at bus-65 in case of Type-1, 2 and 3, respectively. The desirable net saving cost increased to 42313.19 and 32999.84 (\$ per year) in case of Type- 1 and 2, respectively. 
TABLE VI. CROPPED RESULTS AFTER EMPLOYING TWO DGS FOR 33, 69 AND118-NODE SYSTEMS

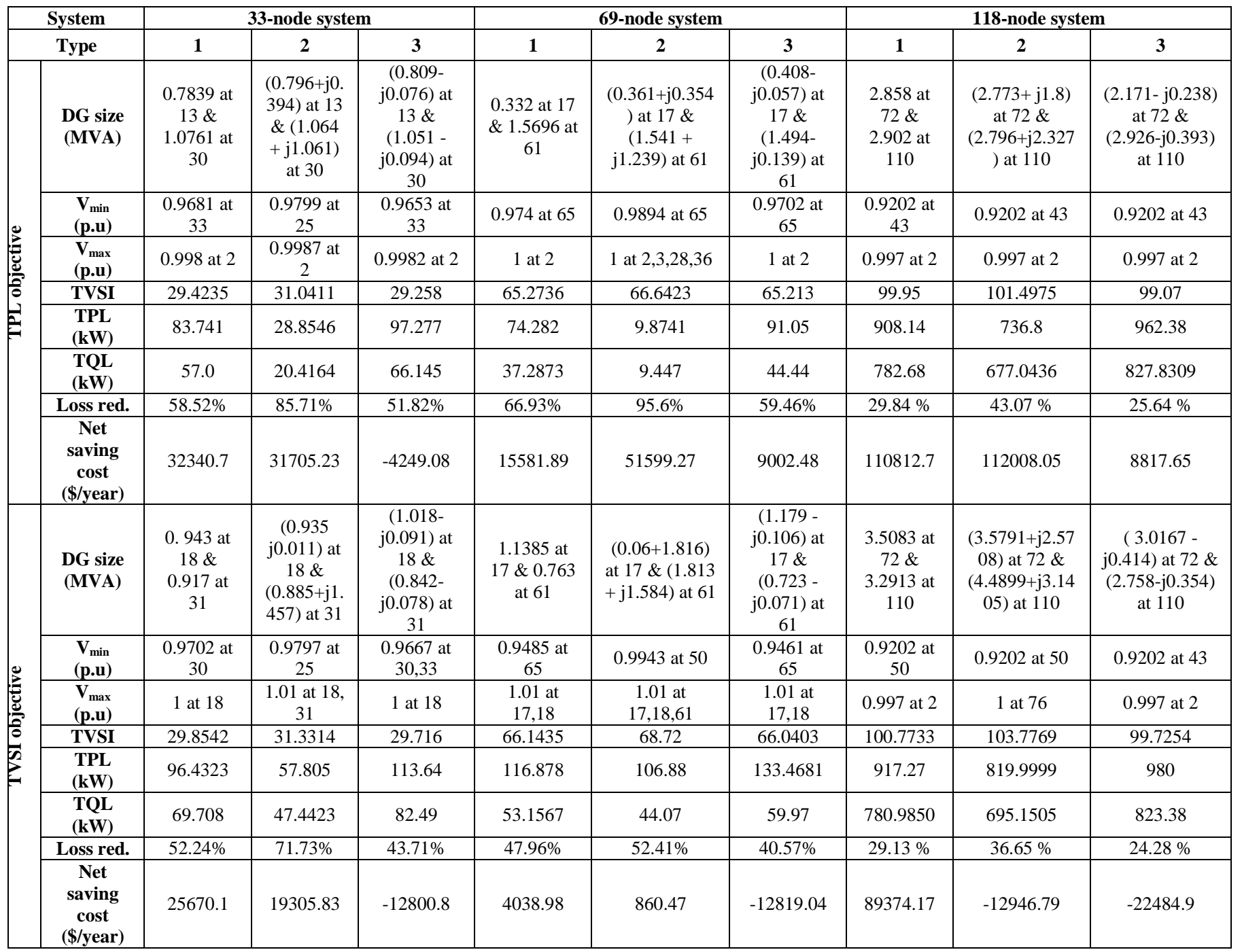

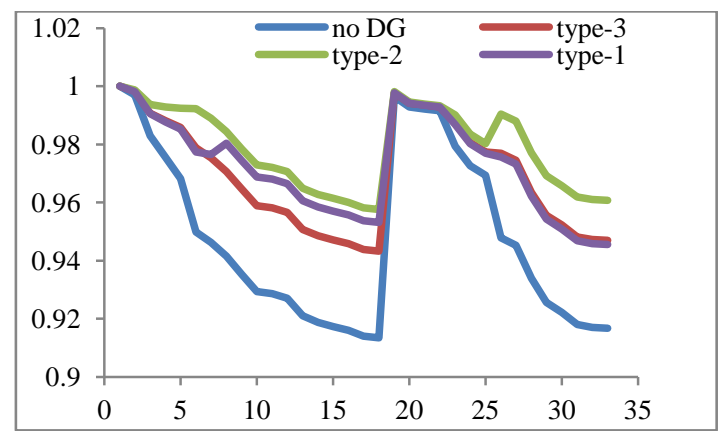

(a) 33-node Network voltage profile without and with 2 DGs (TPLobjective)

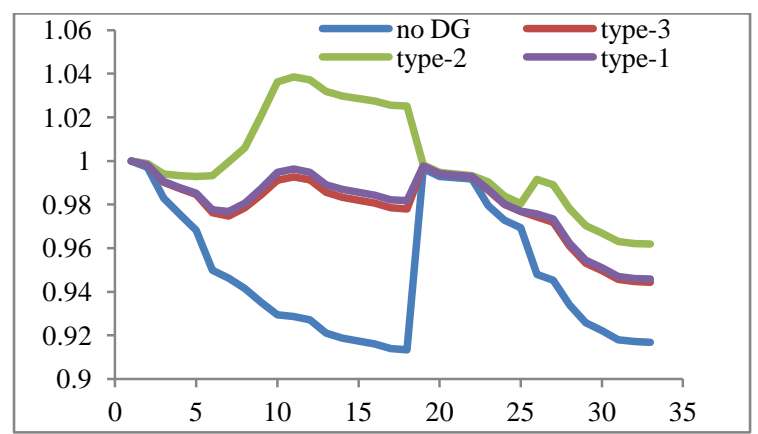

(b) 33-node Network voltage profile without and with 2 DGs (TVSIobjective) 


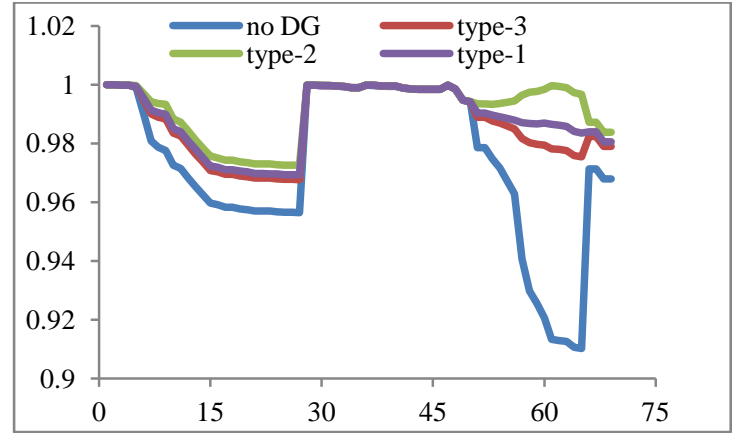

(c) 69-node Network voltage profile without and with 2 DGs (TPLobjective)

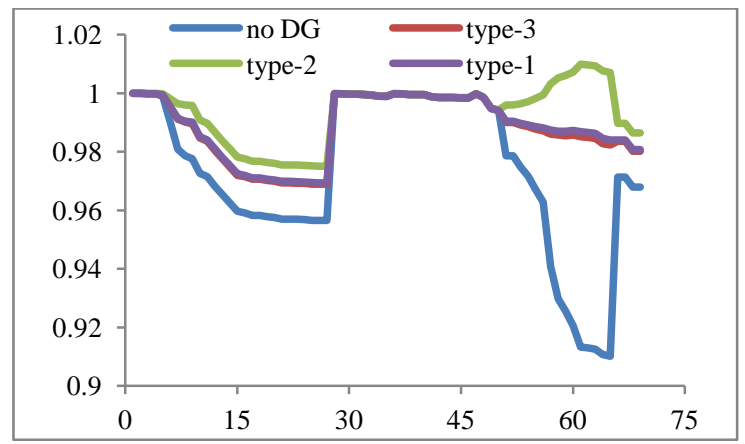

(d) 69-node Network voltage profile without and with 2 DGs (TVSIobjective)

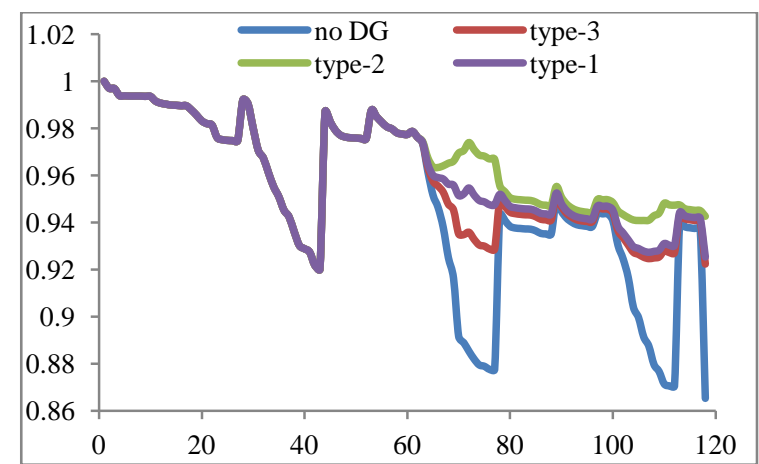

(e) 118-node Network voltage profile without and with 2 DGs (TPL objective)

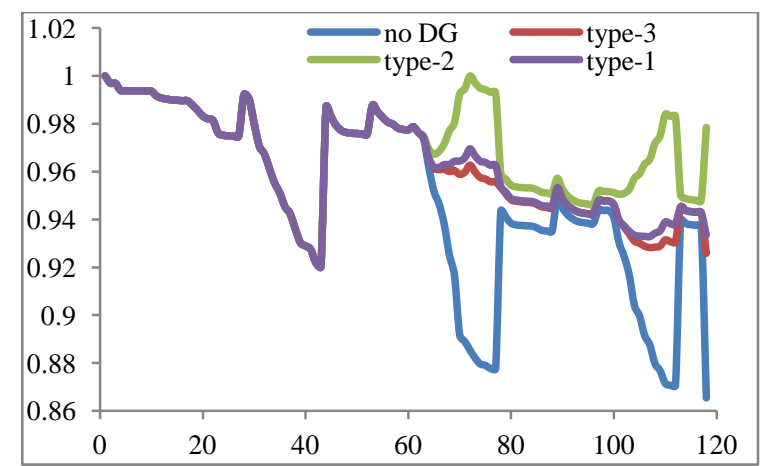

(f) 118-node Network voltage profile without and with 2 DG (TVSIobjective)

Figure 5. networks voltage profile without and with 2 DGs of types 1,2 , and 3
In case of TVSI objective the losses reduction and the net saving costs are less than the values with TPL objective, but the maximum voltage of the system improved higher than maximum voltage with TPL objective.

Table VIII concludes the loss reduction percentage due to install two DGs for 33 and 69-node systems in comparison with the other challenging methods. It is clear, from all of results, the proposed method is capable of generating highly remarkable loss reductions, bus voltages improvement and net saving cost compared to other heuristic based methods. By comparing the 33-node system results, with type-1 DG found the proposed method achieve loss reduction $58.52 \%$, while LSF achieve loss reduction $52.32 \%$, respectively, with penetration level, and without penetration level, our proposed method achieve $58.94 \%$ loss reduction, while other best one achieve $58.52 \%$. With type-2 DG found the proposed method achieve loss reduction $85.71 \%$, near to BSA which achieve loss reduction $86.25 \%$ and more than IA which achieve loss reduction $78.98 \%$ with penetration level, and without penetration level, our proposed method achieve $85.9 \%$ loss reduction, while other best one achieve $58.52 \%$. With type-3 DG found the proposed method achieve loss reduction more than other with and without penetration level.

When comparing the 69-node system results, found the proposed method achieve with penetration level loss reduction 66.93 and $95.6 \%$ for type-1 and 2, respectively, and without penetration level, our proposed method achieve loss reduction 86.63 and $96.79 \%$ for type- 1 and 2, respectively.

Moreover, the fluctuation of daily load profile on the effectiveness of installing one and two DGs to 33,69 , and 118-node systems for TPL objective with the proposed algorithm is evaluated in this paper. Daily loads start from 8 a.m. with $60 \%$ of base load, and increases by $5 \%$ each hour till peak load at 4 p.m. (100\% of base load) at 3 p.m., after that load decrease by $5 \%$ each hour till 12 p.m. to reach $60 \%$ of base load then remains steady till 8 a.m.

Fig. 6 (a), (b) compare the daily TPL with different types of one and two DGs installed in 33-node system, respectively. It noticed from the Figure that, with one type of Dgs, the minimum TPLs are 37.77, 21.67, and 40.08 $\mathrm{kW}$ at night, while the peak TPLs is 109.16, 67.6, and $120.05 \mathrm{~kW}$ for DG type 1,2 , and 3 , respectively. On the other hand, when installing two DGs, the minimum TPLs are $29.53,10.15$, and $35.04 \mathrm{~kW}$, and the peak TPLs are $82.9,28.49$, and $94.9 \mathrm{~kW}$ for DG type 1, 2, and 3 respectively. 
TABLE VII. CROPPED RESULTS AFTER EMPLOYING TWO DGS FOR 33, 69-NODE SYSTEMS WITHOUT PENETRATION LIMITS

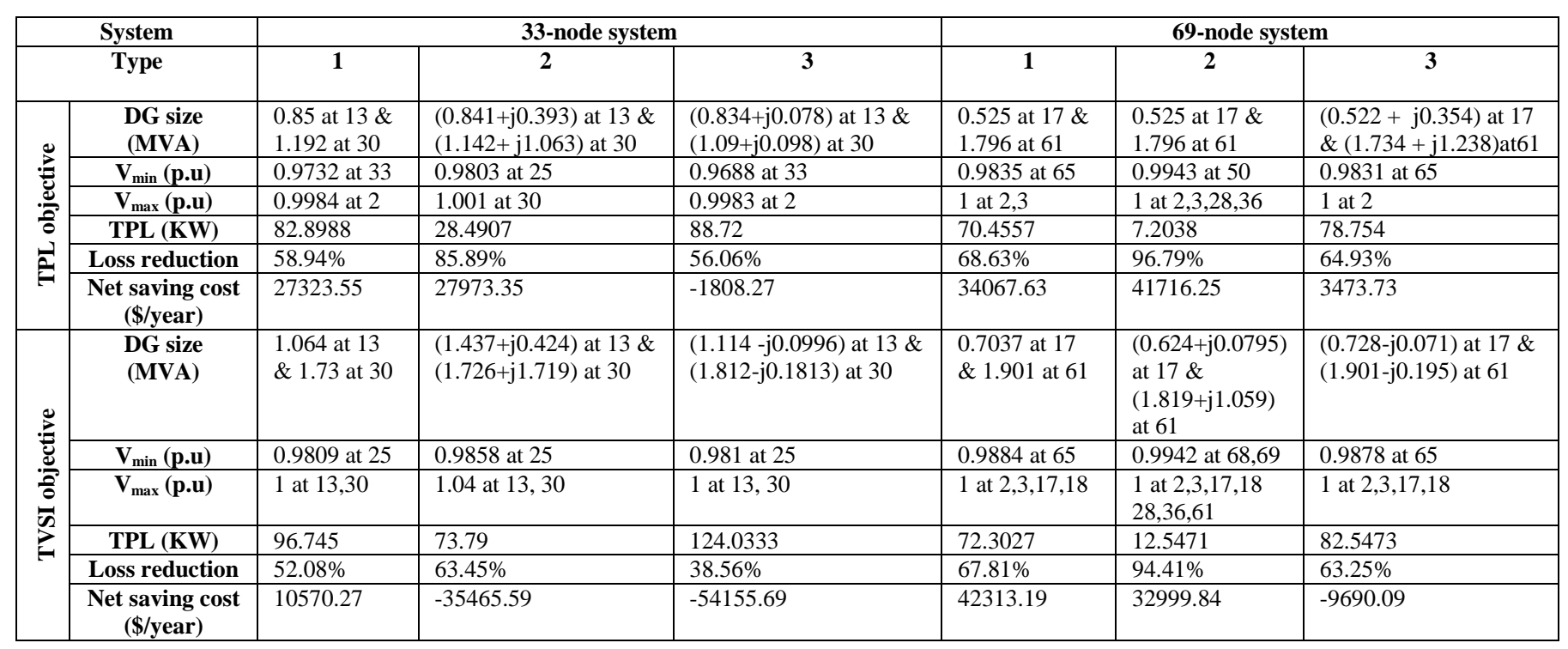

TABLE VIII. COMPARISON OF OPTIMAL RESULTS TO OTHER METHODS FOR 33 AND 69-NODE RDNS WITH TWO DGs (TPL-OBJECTIVE).

\begin{tabular}{|c|c|c|c|c|c|c|c|c|c|}
\hline \multicolumn{6}{|c|}{ 33-node network } & \multicolumn{4}{|c|}{ 69-node network } \\
\hline \multicolumn{2}{|c|}{ DG type-1 } & \multicolumn{2}{|c|}{ DG type-2 } & \multicolumn{2}{|c|}{ DG type-3 } & \multicolumn{2}{|c|}{ DG type-1 } & \multicolumn{2}{|c|}{ DG type-2 } \\
\hline Method & LD\% & Method & LD\% & Method & LD\% & Method & LD\% & Method & LD\% \\
\hline $\operatorname{LSF}[13]^{\mathrm{a}}$ & 52.32 & IA [13] & 78.98 & $\mathrm{BSA}[1]^{\mathrm{a}}$ & 51.35 & $\operatorname{LSF}[13]^{b}$ & 54.97 & IA [13] $]^{\mathrm{a}}$ & 96.69 \\
\hline $\mathrm{BSA}[1]^{\mathrm{b}}$ & 58.37 & PSO [31] ${ }^{b}$ & 86.48 & $\operatorname{ICA}[35]^{b}$ & 50.98 & $\operatorname{ELF}[13]^{b}$ & 67.94 & $\mathrm{ALO}^{\mathrm{b}}$ & 96.79 \\
\hline PSO [31] $]^{b}$ & 58.37 & $\mathrm{ALO}^{\mathrm{a}}$ & 85.71 & $\mathrm{ALO}^{\mathrm{a}}$ & 51.82 & $\mathrm{ALO}^{\mathrm{a}}$ & 66.93 & & \\
\hline $\mathrm{ALO}^{\mathrm{a}}$ & 58.52 & $\mathrm{ALO}^{\mathrm{b}}$ & 85.89 & $\mathrm{ALO}^{\mathrm{b}}$ & 56.06 & $\mathrm{ALO}^{\mathrm{b}}$ & 68.63 & & \\
\hline
\end{tabular}

Fig. 6 (c), (d) compare the daily TPLs with different types of one and two DGs installed in 69-node system, respectively. When installing one DG, the minimum TPLs are $29.07,8.22$, and $34.63 \mathrm{~kW}$ at night, the peak TPLs is $81.54,23.17$, and $98.99 \mathrm{~kW}$ for type 1,2 , and $3 \mathrm{DG}$ respectively. With two DGs, the minimum TPLs are 25.18, 2.58, and $32.04 \mathrm{~kW}$, and the peak TPLs are 74.28, 9.87, and $91.05 \mathrm{~kW}$ for DG type 1,2, and 3, respectively.

Fig. 6(e), (f) compares the daily TPLs with different types of one and two DGs installed in 118-node system, respectively. When installing one DG, the minimum TPLs are $548.54,523.38$, and $556.36 \mathrm{~kW}$ at night, the peak TPLs is 1082.7, 1008.9, and $1113.2 \mathrm{~kW}$ for DG type 1, 2, and 3 , respectively. With two DGs, the minimum TPLs are 494.38, 464.82, and $509.21 \mathrm{~kW}$, and the peak TPLs are 908.14, 736.8, and $962.38 \mathrm{~kW}$ for DG type 1, 2, and 3 , respectively.

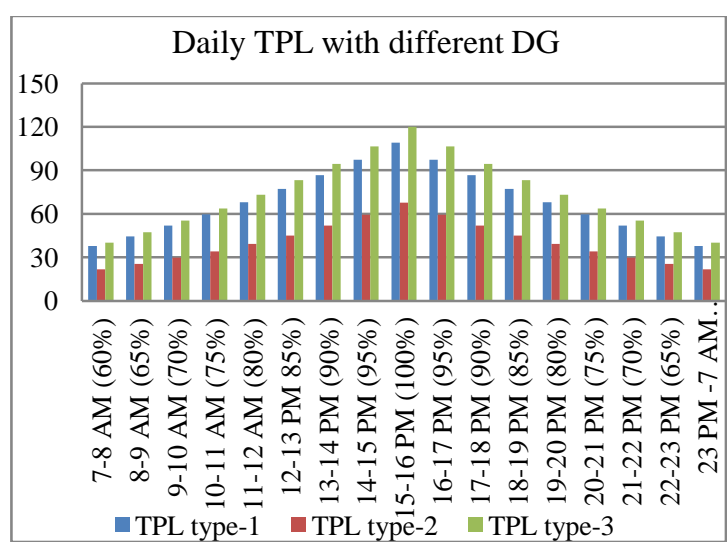

(a) Daily TPL for $33 \mathrm{RDN}$ with different type of DG (one DG). 


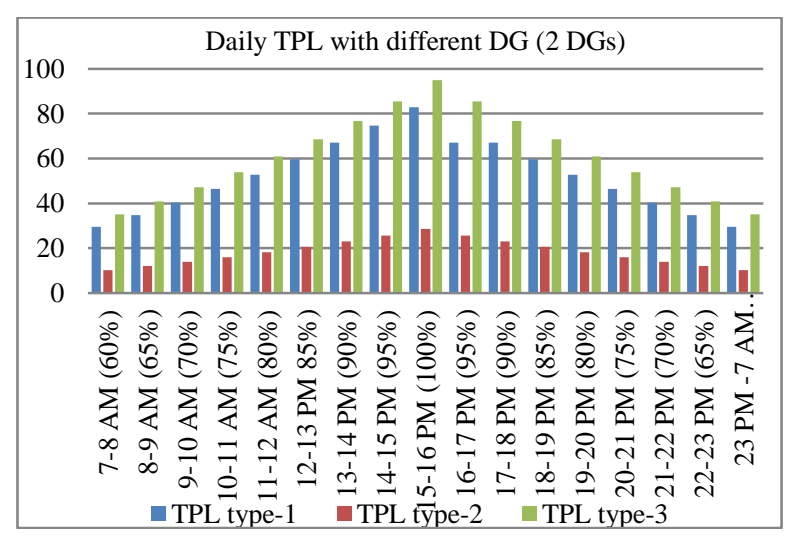

(b) Daily TPL for 33 RDN with different type of DG (two DG)

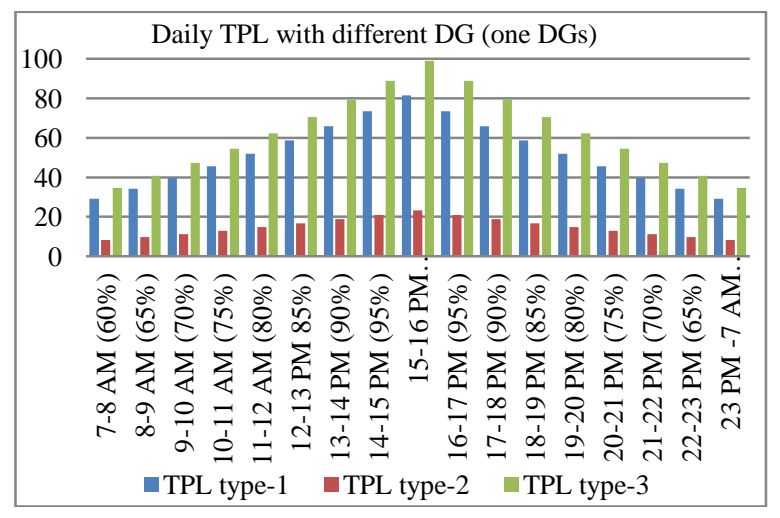

(c) Daily TPL for 69 RDN with different type of DG (one DG)

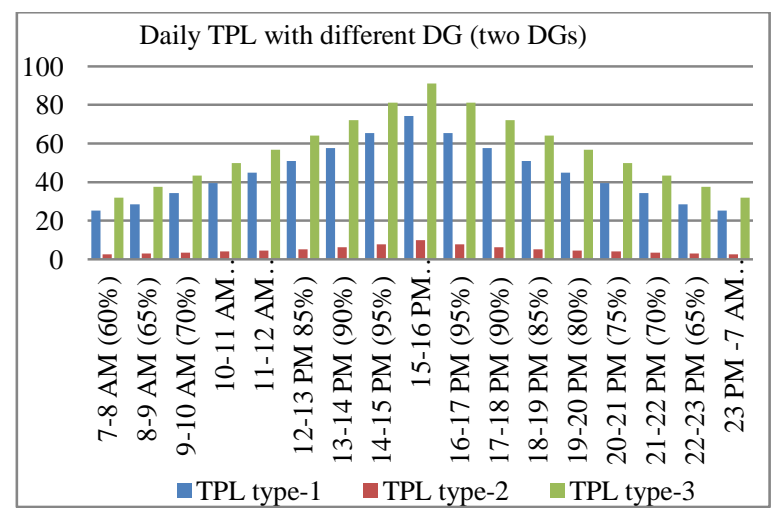

(d) Daily TPL for 69 RDN with different type of DG (two DG)

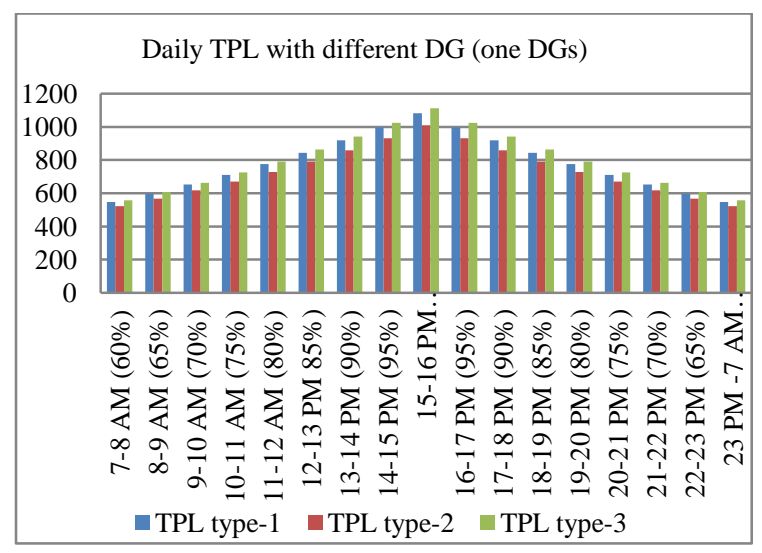

(e) Daily TPL for 118 RDN with different type of DG (one DG)

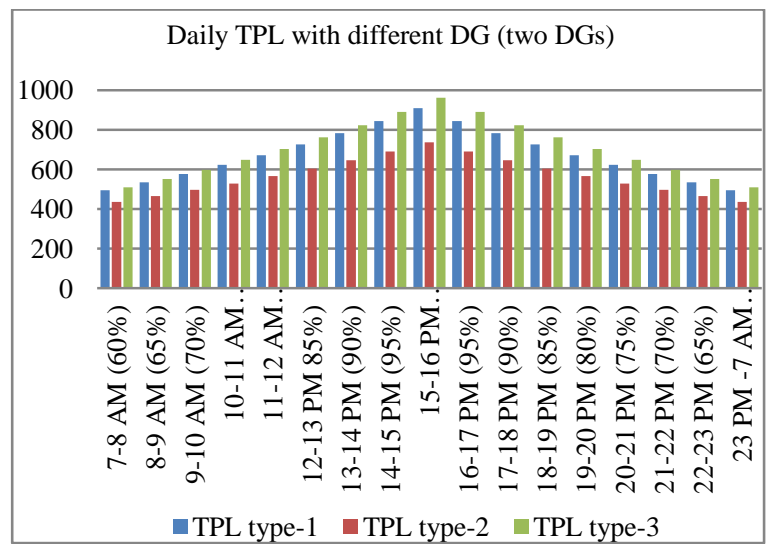

(f) Daily TPL for 118 RDN with different type of DG (two DG)

Figure 6. the networks daily TPLs with DG units of types 1,2 , and 3 for 33, 69 and 118 RDS.

\section{CONCLUSIONS}

In this paper, ALO is used to allocate three different types of DG in RDS. The three types have different characteristics in producing or absorbing reactive power. They have different abilities to reduce system losses and enhance voltage profile. Three test systems are examined which are the 33, 69 and 118 IEEE bus system. The three systems are equipped either with only one type DG or with two types. ALO is used to allocate these DGs in the RDS depending on two indices, the loss sensitivity factor and the voltage stability index. Total voltage deviation and running cost are used to judge the quality of solution in each case study. Reduction in system losses and enhancement of voltage profile are two notable points of strength of the proposed algorithm compared to other competitive metaheuristic techniques in literature. Using two DGs of type 2 resulted in the best performance regarding loss reduction and voltage profile enhancement, especially when considering the daily load cycle. 


\section{REFERENCES}

[1] A. El-Fergany, "Multi-objective allocation of multi-type distributed generators along distribution networks using backtracking search algorithm and fuzzy expert rules", Electric power components and systems, 2016, Vol. 44, No. 3, pp. 252-267. doi:10.1080/15325008.2015.1102989

[2] M. Naresh Babu, S. Nyamathulla and D. C. Sasikala, "Optimal placement \& sizing of DGS using backtracking search algorithm in IEEE 33-bus distribution system", International journal of advanced technology and innovative research, 2016, Vol. 8, No. 20, pp. 39483954.

[3] R. Ishak, A. Mohamed, A. N. Abdalla, M. Zamri and C. Wanik, "Optimal DG placement and sizing for voltage stability improvement using backtracking search algorithm", Int'l conference on artificial intelligence, energy and manufacturing engineering (ICAEME'2014), June 9-10, 2014, Kuala lumpur (Malaysia), pp. 29-34.

[4] F. S. Abu mouti and M. E. Elhawary, "Optimal DG placement for minimizing power loss distribution feeder systems using sensorydeprived optimization algorithm", 24 th Canadian conference on electrical and computer engineering (CCECE), Niagara falls, Canada, May 8-11, 2011, No. 52, pp. 1-10, doi: 10.1109/CCECE.2011.6030439

[5] K. Dhananjaya and A. Devi., "Cost effective distributed generation placement and sizing using water flow-like algorithm," Power and Energy System: Towards Sustainable Energy (PESTSE), Biennial international conference, Jan 21-23, 2016, pp. 1-6. doi: $10.1109 /$ pestse. 2016.7516370

[6] W. S. Tan, M. Y. Hassan, M. S. Majid, and H. A. Rahman, "Allocation and sizing of DG using Cuckoo Search algorithm," IEEE International conference on power and energy (PECon), Magellan sutera resort kota kinabalu, Malaysia, Dec. 2-5, 2012, pp. 133-138. doi: 10.1109/PECon.2012.6450192

[7] S. Vasanthakumar, N. Kumarappan , R. Arulraj , and T. Vigneysh "Cuckoo Search Algorithm based environmental economic dispatch of microgrid system with distributed generation," Smart technologies and management for computing, communication, controls, energy and materials international conference (ICSTM), Vel Tech Rangarajan Dr.Sagunthala R\&D Institute of Science and Technology Avadi, Chennai, TamilNadu Chennai, India, May 6-8, 2015 , pp.575-580. doi: 10.1109/ICSTM.2015.7225481

[8] M. H. Moradi, M. Abedini, and S. M. Hosseinian. "A combination of evolutionary algorithm and Game theory for optimal location and operation of DG from DG owner stand point," IEEE transactions on smart graid, 2015, Vol. 7, Issue. 2 , No. TSG-00875-2014 , pp. 608 - 616, doi: 10.1109/TSG.2015.2422995.

[9] K. Mahmoud, N. Yorino, and A. Ahmed "Optimal distributed generation allocation in distribution system for loss minimization," IEEE Transactions on power systems, 2015, Vol. 31, Issue. 2, No. TPWRS-00835-2014, $\quad$ pp. 960 - 969, doi: 10.1109/TPWRS.2015.2418333.

[10] P. Akayol, A. Seena and C. Chanda. "Optimal location, type and size selection technique of distributed generation based on economic index," Energy efficient technologies for sustainability international conference (ICEETS), Nagercoil, India, Apr 10-12, 2013, Vol. 60, No. 4, pp. 989-994. doi. 10.1109/ICEETS.2013.6533521

[11] J. Rajalakshmi and S. Durairaj "Review on optimal distributed generation placement using particle swarm optimization algorithms," Emerging trends in engineering, technology and science international conference (ICETETS), Pudukkottai, India, Feb. 24-26, 2016, pp. 598-603. doi: 10.1109/ICETETS.2016.7603088

[12] T. Bouktir and F. Abbas "Optimal allocation and sizing of distributed generation with particle Swarm optimization algorithm for loss reduction," Revue des sciences et de la technologie - RST-, 2015, Vol. 6, No. 1, pp. 58-69.

[13] D. Rama, R. Ageshvaran, E. Raghunath and G. Raghuran, "Determining the optimal location and sizing of distributed generation unit using Particle Swarm Optimization Algorithm", International conference on computer communication and informatics (ICCCI-2012), Coimbatore, India, Jan. 10-12, 2012, doi: 10.1109/ICCCI.2012.6158888, pp.1-7.

[14] D.Q. Hung, N. Mithulananthan, and R. C. Bansal, "Multiple distributed generators placement in primary distribution networks for loss reduction," IEEE Transactions on industrial electronics, 2013, Vol.60, No.4, pp.1700-1708, doi:10.1109/TIE.2011.2112316.

[15] M. Shahzad , I. Ahmad, W. Gawlik, and P. Palensky, "Load concentration factor based analytical method for optimal placement of multiple distribution generators for Loss minimization and voltage profile improvement", Energies, 2016, Vol. 9, No. 287, pp. 1-21, doi:10.3390/en9040287

[16] H. Nasiraghdam, and S. Jadid, "Load model effect assessment on optimal distributed generation (DG) sizing and allocation using improved harmony search algorithm", Smart grid conference (SGC), 2013, Tehran, Iran, Dec 17-18, 2013, pp. 210-218. doi: 10.1109/SGC.2013.6733810

[17] W. Sun and X. Chang "An improved harmony search algorithm for power distribution network planning," Journal of electrical and computer

Vol. 2015 (2015), No. 5, pp. 37-42.

[18] P. Hemalatha and V. Usha Reddy, "Optimal placement of DG in distribution networks using fuzzy and HSA", Discovery the international daily journal, 2015, Vol. 2015, No. 46(213), pp. 87-92.

[19] E. Naderi, "A dynamic approach for distribution system planning considering distributed generation", IEEE Transactions on power delivery, July 2012, Vol. 27, No. 3, pp.1313-1322. doi: 10.1109/TPWRD.2012.2194744

[20] S. Selvi and R. Shmi, "Optimal sitting and sizing of distributed generation using Fuzzy-Ep”, IEEE 2011 International conference on recent advancements in electrical, electronics and control engineering, Mepco Schlenk Engineering College, Sivakasi India, Dec 15-17, 2011, pp. 470-477. doi: 10.1109/ICONRAEeCE.2011.6129770

[21] R. Singh, G. Brar and N. Kaur, "Optimal placement of DG in radial distribution network for minimization of losses", International journal of advanced research in electrical, electronics and instrumentation engineering, Aug. 2012, Vol. 1, Issue 2, No. 9, pp: 84-90.

[22] E.S. Ali, S.M. Abd Elazim, A.Y. Abdelaziz, "Ant lion optimization algorithm for renewable distributed generations", Energy journal, 2016, Vol. 116, pp.445-458. doi: 0.1016/j.energy.2016.09.104

[23] I. N. Trivedi, P. Jangir and S. A. Parmar, "Optimal power flow with enhancement of voltage stability and reduction of power loss using ant-lion optimizer", Cogent engineering, 2016, Vol. 3, No. 1, pp. 118. doi: $10.1080 / 23311916.2016 .1208942$

[24] K. Javad and T. Vahid, "Multi-objective distribution network operation based on distributed generation optimal placement using new antlion optimizer considering reliability", Journal of electrical and electronics engineering, 2016, Vol. 9, No. 2, pp: 31-36.

[25] A. El-Fergany, "Optimal allocation of multi-type distributed generators using backtracking search optimization algorithm", International journal of electrical power energy system, 2015, Vol. 64, pp.1197-1205. doi: 10.1016/j.ijepes. 2014.09.020

[26] S. Kansal, B. Sai., B. Tragi, and V. Kumar, "Optimal placement of wind-based generation in distribution networks", IET Conference on renewable power generation (RPG 2011), Edinburgh, united kingdom, Sep. 6-8, 2011, pp. 229-234. doi:10.1049/cp.2011.0141

[27] S. Sunisith1, K. Meena, "Backward/Forward sweep based distribution load flow method", International electrical engineering journal (IEEJ), 2014, Vol. 5, No.9, pp.1539-1544

[28] S. Mirjalili "The ant lion optimizer," May 2015, Science direct, 2015, Vol. 83, pp. 80-98. doi: 10.1016/j.advengsoft.2015.01.010

[29] The MathWorks, available at: http://www.mathworks.com, visited on Thursday, September 10, 2015 at 8:30 PM.

[30] http://www.nrel.govanalysistech_cost_dg.html, visited on Tuesday, March 22, 2016 at 11:37 AM.

[31] A. A. Bagheri, A. Habibzadeh, and S. M. Alizadeh,"'Comparison of the effect of vombination of different DG types on loss reduction using APSO algorithm", Canadian journal on electrical and electronics engineering, 2011, Vol. 2, No. 10, pp. 468-674.

[32] F. S. Mouti, and M. E. El-Hawary, "Optimal distributed generation allocation and sizing in distribution systems via artificial bee colony 
algorithm', IEEE transactions power delivery, 2011, Vol. 26, No. 4, pp. 2090-2101. doi: 10.1109/TOWRD.201102158246

[33] A. A. Elbaset, M. Mosaad, M. G. Ashmawy, "Optimal allocation of DG considering enhancement of distribution system performance using artificial intelligence", 17th International middle-east power system conference (MEPCON'15), Mansoura university, Egypt, December 15-17, 2015, No. 1007, pp.1-5.

[34] M. Rostamzadeh, K. Valipour, S. Shenaval, M. Khalilpour, and N. Razmjooy, "Optimal location and capacity of multi-distributed generation for loss reduction and voltage profile improvement using imperialist competitive algorithm", Artificial intelligence Research, 2012, Vol. 1, No. 2, pp.56-66. doi: 10.5430/air.v1n2p56 